Portland State University

PDXScholar

$10-28-2021$

\title{
Japanese-English Code-Switching by Postwar Speakers in Contemporary America
}

Andre John Shepherd

Portland State University

Follow this and additional works at: https://pdxscholar.library.pdx.edu/open_access_etds

Part of the Asian Studies Commons, and the Discourse and Text Linguistics Commons Let us know how access to this document benefits you.

\section{Recommended Citation}

Shepherd, Andre John, "Japanese-English Code-Switching by Postwar Speakers in Contemporary America" (2021). Dissertations and Theses. Paper 5869.

https://doi.org/10.15760/etd. 7740

This Thesis is brought to you for free and open access. It has been accepted for inclusion in Dissertations and Theses by an authorized administrator of PDXScholar. Please contact us if we can make this document more accessible: pdxscholar@pdx.edu. 
Japanese-English Code-Switching by Postwar Speakers in Contemporary America

by

Andre John Shepherd

A thesis submitted in partial fulfillment of the requirements for the degree of

\author{
Master of Arts \\ in \\ Japanese
}

Thesis Committee:

Suwako Watanabe, Chair

Jon Holt

Karen Curtin

Portland State University

2021 


\begin{abstract}
In her examination of Japanese-English bilingualism in Toronto, Nishimura (1995b) demonstrated that second-generation Japanese-Canadians varied their speech dependent on the audience they were addressing. According to her, the JapaneseCanadians spoke primarily in English to fellow second-generation speakers, while maintaining conversations in Japanese with those who had spent their formative years in Japan. However, when addressing audiences composed of both groups, they switched back and forth evenly between the two languages.
\end{abstract}

Following research done by Woolard (1989) on the effects of societal influences on language, the state of the Japanese-Canadians can be related to the breakup of the ethnic enclaves in which they had lived prior to the onset of World War II, also described by Nishimura (1995a). In contrast, this study examines the language used by more recently arrived Japanese-American speakers, whose families had not undergone the political instability of earlier generations. Three groups of these postwar JapaneseEnglish speakers, each consisting of one native speaker and two Japanese-American heritage speakers, provided the data for the study via conversations that were recorded during an internet call. These speakers came from a variety of educational backgrounds, and often spent at least some time in both Japan and the U.S.

Following Myers-Scotton (1993), this study claims the diversity of parts of speech being used inside of one clause is a reliable metric that can be used in order to categorize a bilingual's speech. Using this method, the study finds that all of Nishimura's forms of bilingual speech are still being used among contemporary Japanese-Americans: a mostly 
Japanese version, a mostly English version, and a version in which the two languages are more evenly combined. The first two variants consist of the primary language with the occasional use of mostly single words from the other language, while the third contains a greater variety of grammatical items from both languages, and even grammatical overlaps that are not easily explainable in either language. Lastly, unlike the second-generation Japanese-Canadians from pre-war Japanese ethnic neighborhoods, who switched equally between Japanese and English when speaking to native speakers and fellow Japanese Canadians, the postwar second-generation Japanese-Americans in this study use primarily English in the same contexts. This occurs in spite of a consistently high opinion concerning the use of Japanese as held by the postwar speakers. Although the existence of the three variants of bilingual speech is confirmed among postwar JapaneseAmericans, the choice of which variant to use is not dependent on the generation the speaker belongs to, but more concretely on the extent to which the speakers themselves were educated in Japan. 
Dedication

To the Nikkei and Hafu Communities of America 


\section{Acknowledgments}

I would like to express my sincere gratitude to the following people:

My thesis adviser, Dr. Suwako Watanabe for the patience and concern in guiding me in the development of this thesis, particularly in helping me to finish this paper on a tight schedule. All of my efforts would have been in vain without her help, which has made it possible for me to enter the world of empirical studies in one piece. I would also like to thank Dr. Jon Holt for exposing me to the modern classics of Japanese literature as well as the beginnings of an appreciation of its grammar, which ultimately lead me to pursue this path. Similarly, I am grateful to Dr. Karen Curtin for introducing me to sociolinguistics and to the scientific method in the humanities; this paper would not have been possible without her instruction. Finally, I would like to thank Mori Wilhite and Sachi Kobayashi for their invaluable connections to the participants, as well as the participants themselves. 
Table of Contents

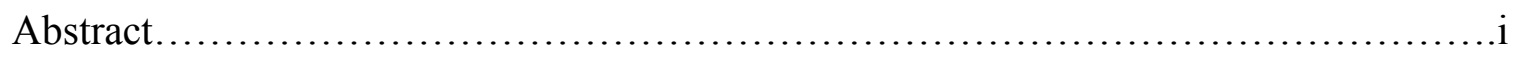

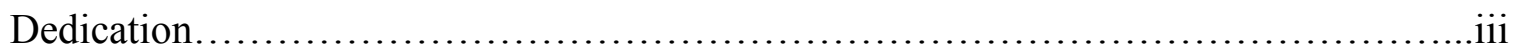

Acknowledgements.......................................................

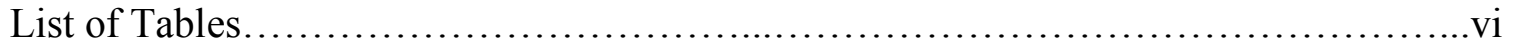

Chapter 1

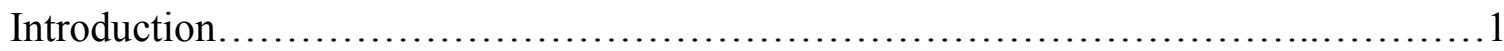

Chapter 2

Literature Review............................................................

Chapter 3

Methodology ..............................................................20

Chapter 4

Data Analysis................................................................ 37

Chapter 5

Discussion and Conclusion......................................................61

References.............................................................. 77

Appendix A. Transcription Conventions..................................... 79

Appendix B. Conversation and Interview Transcript............................. 80 


\section{List of Tables}

Table 1

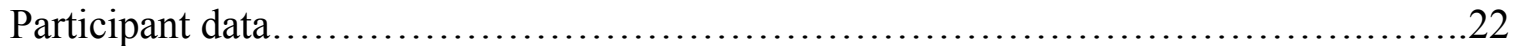

\section{Table 2}

Subdivisions of code-switching............................................. 34

\section{Table 3}

Morphemes of each group conversation...................................... 37

Table 4

Total of code-switches per participant by group.

Table 5

English-to-Japanese code-switches........................................... 43

Table 6

Japanese-to-English code-switches.......................................... 45 


\section{Chapter 1}

\section{Introduction}

This study will examine the language use of postwar Japanese-English speakers living in America based on their use of code-switching. The nature of bilingual speech does not seem to be uniform across time, but are composed of the two languages in varying ways depending on the social context the speakers are raised in. This study questions whether Japanese-Americans are a good example of such variation, and that noticeable linguistic differences could be detected depending on the society each generation is raised in. Code-switching, or "the use of two language varieties in the same conversation" (Myers-Scotton 2006, 239) is presented here as a means of measuring these variations.

Woolard (1989) suggests that the use of a language depends on the political and social circumstances of a given culture. Following this line of thought, the study seeks to discover whether the behavior of Japanese-English heritage speakers living in the Continental U.S. will vary depending on whether the first generation of speakers came prior to or later than the breakup of the Japanese-American neighborhoods. Contrary to earlier observations of speakers from communities established prior to the internment camps, it may be possible that heritage speakers whose families did not undergo this kind of tribulation may not share the same set of linguistic presuppositions and norms.

Following this line of thought, this study will examine whether this later group will use 
Japanese to a greater extent than in the past, as evidenced by a lower rate of codeswitching.

This study arises from my own personal interest in the case of contemporary Japanese-American culture. I myself come from a family of Japanese heritage speakers who are more recent arrivals and do not share the same lineage and history as the original Japanese-Americans who lived through the wartime U.S. As a result, I have never felt that earlier descriptions of Japanese-American life, which tended to focus on families with a longer history in the U.S., actually described the culture my relatives seemed to have had. Therefore, this study wishes to focus on these more recent arrivals, whom I generally call "postwar speakers," in order to see if there is any significant difference in speech patterns from earlier immigrants. 


\section{Chapter 2}

\section{Literature Review}

In this chapter, I will summarize some of the basic studies on code-switching in the literature, beginning with the linguistic papers that first introduced the meaningfulness of studying code-switching. From there, I will address interactional sociolinguistics, or the study of how personality and identity are expressed through language, followed by its connection to the study of ideology in language. Next, I will also take a look at attempts to explain code-switching rigorously in grammatical or quantitative terms. Afterwards, I will address studies of Japanese-English code-switching more particularly, and show how they compare with attempts to explain code-switching in other languages. Last of all, I will examine language contact studies and show that code-switching can be used to account for different stages of integration between two languages, and, I will show how this applies to earlier studies of Japanese-English bilingualism as well.

\subsection{Fundamentals of Code-Switching in Early Sociolinguistics}

The issue of code-switching pursued here falls under the banner of sociolinguistics. This branch of linguistics was largely codified into its current form due to the research of the anthropologist John Gumperz (1982), who sought to account for the influence of culture on variation in speech. He contrasts his approach with that of earlier generative grammarians, who argued that regional variants of speech were more or less

meaningless and a distraction from the fundamental structure of each language. Gumperz, 
however, held that all such variations in speech may actually have meaning and are worthy of study, including the phenomenon known as code-switching, in which bilingual speakers alternate between the use of two languages or language variants, sometimes even in the middle of a sentence.

Gumperz initiated the study of code-switching by proposing in his study of dialects in Norway with Peter Blom that code-switching may have meaning in expressing the social affiliations of the bilingual speakers, showing whether they feel fellowship with other speakers of the same dialect, or are expressing distance and formality. The study concentrated on a small town in northern Norway, Hemnesberget, in which the residents used both a local dialect, Ranamal, as well as one of the official forms of the Norwegian language, Bokmal. Rather than see these two languages as completely disparate, Gumperz and Blom (1972) claimed that they were "two varieties of code" that together made up "a single linguistic system” (preface, 408). Following the earlier work of Labov (1972) who studied dialect differences in New York, they held that just as any two words of the same language could differ in sound and meaning yet be in the same language, so also could two languages be combined as codes, or languages with social nuances attached to them, into an even larger set of norms. Gumperz and Blom established this by first confirming the distinctness of the two dialects based on actual differences in sound and grammar, and then showed that the differences were slight enough to be accounted for by one overarching grammatical system. Furthermore, rather than explain the use of the two dialects on the basis of "intelligibility," they instead showed that these two forms were used depending on social context (416). 
For instance, Gumperz and Blom associated each dialect with the place it was learned; the local dialect carried connotations of the home and local life, whereas the official language was learned and used in the school system, and was associated with public life. To describe this, they coined the term "social meaning" to refer to "the social value implied when an utterance is used in a certain context" (417). In this way, they sought to show that inference of meaning was not only dependent on the words that the speaker used, but was also dependent on the place or "setting" in which the conversation occurs (422).

In the context of the study, the local dialect had the connotation of solidarity and was well regarded amongst the people of the village, whereas the use of the official dialect could come across as snobbish when the locals used it amongst each other. The two researchers noticed that the locals would use one dialect or the other depending on the level of formality of the conversation and the time and place in which it occurred, and referred to this kind of code-switch as "situational switching" (424). However, they also noticed changes in topic would also involve code-switching as well, even when the circumstances did not change significantly, and referred to this second kind as "metaphorical switching” (425).

Gumperz continued and expanded upon the results of his earlier study with an examination of code-switching in chapter four of his work Discourse Strategies (1982). For example, in this book he introduced the terminology of "we-code" and a "they-code," which corresponded to the private and public uses of dialect that he and Blom had noticed in their earlier study (66). However, instead of focusing on bilingual speech in 
which two distinct languages are used by the same speaker in different situations, as he did in the earlier study, Gumperz also examined what he called "conversational code switching," or speech in which code-switches would occur in immediate succession, between sentences and even in the middle of sentences in a conversation (61). Furthermore, in this work he outlined not only the social usefulness of code-switching, but also included a theory of grammatical constraints and rules governing its use.

First, Gumperz attempted to establish that this kind of code-switching actually carries meaning in bilingual conversation. He referred to dialogue from three separate previous studies, Slovenian-German conversation, Hindi-English dialogue, and Chicano Spanish-English conversations, in which Slovenian, Hindi, and Spanish are the speech of the in-group, or "we-code" as opposed to English and German, which constituted the more formal "they-code." In examining the dialogue of these three very different language pairs, he noticed that many of the code-switches would happen at similar points in all three of the dialogues, for instance, to mark off quotations, to repeat or emphasize a point already made in a different language, or when turning to address a third party. Though he held that these code-switches might support the existence of a limited set of universal rules governing switches, he ultimately held that these rules were very complex and dependent on the particular situation in which they took place.

Similarly, he also attempted to form some grammatical rules that would govern code-switching generally. He proceeded by taking sections of these dialogues, and then forming similar dialogues in which the switches happened at different times. These in turn were given back to native speakers, who would in turn judge them for naturalness. 
Although code-switches did at times occur in constituents or in the groupings discovered by previous research on syntax, such as relative clauses and prepositional phrases, Gumperz held that the grammar of code-switching was governed more by pragmatic or meaning-based rules than grammatical structure, though these pragmatic rules could also apply to multiple pairs of languages. For example, in his research on Hindi-English switches, he discovered that native speakers of Hindi felt that a father talking to his son who switches from Hindi to English sounded threatening, whereas the father would sound kinder to the bilinguals when Gumperz showed them the same dialogue, only this time switching from English to Hindi. Similar reactions also took place in EnglishSpanish parental conversations, showing that switches to the "they-code" tended to sound harsher. In this way, his work helped give rise to two different traditions for studying code-switching: one that focuses on the meaning of a switch relative to the bilingual society in which it takes place, and another that focuses on the possibility of a universal grammar and syntax governing these switches.

\subsection{Code-Switching in Interactional Sociolinguistics}

Gumperz' (1982) influence on societal rules and strategies for conveying meaning extended beyond code-switching into the study of interactional sociolinguistics, or the study of how personalities or societal roles are developed in language generally. This branch of sociolinguistics generally tended to focus on language in particular circumstances or on situations in which a quantitative approach aimed at broad generalizations could not capture a moment embodying the relationship between societal rules and language use. For example, Tannen (2005) showed that even speakers who 
spoke the same dialect or language could have vastly different techniques to convey meaning and presuppositions for how to interpret the meaning of a given conversation, a fact which she referred to as conversational style, or "the basic tools with which people communicate." This included features such as turn-taking and intonation (Ch. 1, par. 2).

Although much of linguistic style could be reduced to the quirks of the individual, it could also be based on societal presuppositions and be shared by speakers from a similar culture. She demonstrated this through an analysis of a Thanksgiving dinner conversation between herself and her friends in which she characterized the speech of herself and her other friends who were also from New York as showing "high involvement," as opposed to those who were from other English-speaking regions, who instead showed "high-considerateness" (Ch. 1, par. 5). The New York speakers, for instance, tended to have shorter pauses in their conversation, which in turn caused the other speakers to feel cut off, since they expected a longer time interval between turns in the conversation. Although both sides in the conversation had rules for courtesy and expectations on how conversation was to take place, the difference in these rules made it difficult to have a normal conversation. In this sense, Gumperz' discoveries could apply not only to obviously different languages or regional dialects, but also to any different set of linguistic norms. The whole notion of a linguistic code could even apply to situations in which the speakers apparently spoke the same language.

In the realm of studies of the Japanese language, Minegishi Cook (2008) applied this idea to the study of Japanese style-switching. Unlike Gumperz, who attempted to show that stylistic choices in language could be reduced to changes in the topic or social 
context, Minegishi Cook held that a speaker who switches between formal and informal speech is not mechanically following any particular rule, but "strategically chooses a particular linguistic form to display a particular social persona" (15). She showed that this was the case by examining conversations between professors and students, in which the students finished their instructor's informal sentences with formal speech, showing that the students also participated in establishing the formality of the situation.

Similarly, Maynard (2008) examined the different degrees of formality in Japanese used as speech styles in order to evoke different emotions in internet posts. For instance, in the context of an informal essay, she noticed that writers occasionally would make use of more formal styles in order to convey seriousness or irony depending on whether such speech is appropriate for the social context. This could also be achieved by embedded quotes, in which a person speaking informally could quote someone who is speaking formally, in effect temporarily borrowing their personality. Just as variations between two different languages could be used to express identity, so the use of different levels of formality in the same language could be used to express the same thing.

Lastly, Okamoto (2008) carried out an analysis of discourse which was similar to Gumperz and Blom's original study of code-switching (1972), in which she examined the use of the Yamaguchi dialect as compared to the official language. In this study, she observed the conversations of two female Yamaguchi residents with locals of various social standings. Similarly to Gumperz' observations, the two women used the standard Japanese dialect in polite or formal contexts, and used the dialect with more familiar interactions. However, Okamoto further suggested that the expression of identity might 
be influenced by the heavy hand of language ideology as expressed in the official forms of the language. Therefore, although language might be used as a form of self-expression, it could also be curtailed and used as a tool for political assimilation and power as well.

Just as the early work of Gumperz later branched off into interactional sociolinguistics, so also would dialectology become irrevocably tied with the larger concerns of politics and language ideology. Woolard (1989), also cited by Okamoto, put great emphasis on the nature of language ideology in her study of the Catalan language. For instance, she noted that a regional Spanish dialect such as Catalan was able to assert its existence against the language policies of the national Spanish government precisely because Catalan speakers had such strong opinions about the value of their language, as well as a great deal of political power at the local level, which they in turn used against the poorer Spanish speakers living in their region. She directly contrasted her results with Gumperz and Blom (1972), showing that the Catalan speakers of Barcelona, who are in the minority in Spain, do not use the majority dialect (Castilian), when they are discussing official matters. Whereas in Gumperz and Blom's study, the speakers of the two language variants switch to the official language when talking about official matters. Furthermore, since speaking Catalan was viewed as a socially desirable trait, Catalonians only occasionally switched to Castilian in intimate conversations for emphasis, and mostly used Castilian to those considered outsiders. In this case, not only could political concerns motivate people to use language as a tool in the struggle for power with social inferiors, it could even be strong enough to resist linguistic repression from above.

\subsection{Grammatical Constraints of Code-Switching}


As opposed to the more anthropological approach taken by Gumperz, the first major attempt at a comprehensive explanation of the grammar of code-switching was Sankoff and Poplack (1981). In particular, they were interested in code-switching that occurred in the middle of a sentence or a word, which is called intra-sentential codeswitching, because it was unclear which of the two languages involved were being used to organize this kind of speech. Based on generalizations from data involving EnglishSpanish speaking Puerto Rican bilinguals in New York, they sought to reduce all variations in code-switching to a handful of rules, in an attempt to show that codeswitching was not a haphazard, supposedly degenerate form of speech, but was governed by logical rules much like all other forms of language. Under one such rule, the Free Morpheme Constraint, they posited that switches could not happen in the middle of the word if the switched part is phonologically different, or cannot be pronounced easily in the second language. For instance, they postulated that the possible Spanish-English form "run-eando," equivalent to the word "running," and a participle made up of both languages, could not exist because of the phonological incompatibility of the parts. On the other hand, the form "flipeando" ("flipping"), which could more easily be pronounced in Spanish, was possible and was practically considered a Spanish form by the authors (4). On the whole, they claimed that speech involving code-switching acted as if it belonged to a third language that was composed of the rules of each of the two languages. However, they courted controversy by claiming that code-switching could only take place between languages with a similar word order, a rule they called the Equivalence Constraint. 
Although Sankoff and Poplack (1981) had established their point that codeswitching grammar was worthy of systematic study, the controversy surrounding the Equivalence Constraint forced scholars to produce a stricter or narrower definition of code-switching. Poplack, for example, argued that all forms of language combination involving languages with entirely different word orders could only be considered "'nonce' borrowings," or temporary borrowing (Myers-Scotton 2006, 254). In other words, the use of code-switching in such languages would not be fundamentally different from the use of common foreign loanwords, such as the Japanese word "sushi" in English. In response, Myers-Scotton (2006) developed a new account of code-switching, called the Matrix Language Frame model (hereafter MLF), which permitted code-switches in languages of differing word order. The MLF model holds that at least one language is always dominant, or the "matrix language," and provides most of the rules for what switches are allowed at any given time. This system allowed parts of words, called morphemes, from the Embedded Language, or second language, to take part in the structure of the matrix language (235). This system would account both for combinations of parts of words, such as Sankoff and Poplack's "flipeando" from above, as well as combinations of grammatically different languages such as Japanese and English.

\subsection{The Case of Japanese and English in the Study of Code-Switching Syntax}

In the realm of studies of English-Japanese code-switching in North America, Nishimura used both interactional linguistics and grammatical analysis to study the linguistic behavior of Nisei (second-generation) Japanese-Canadian speakers in Toronto. Disagreeing with Poplack's (1981) assertion that languages of different word order could 
not undergo code-switching, she demonstrated that Japanese-Canadians produced sentences with grammar and words from both English and Japanese simultaneously (1995b). She recorded a conversation among three Japanese-Canadian speakers, whom she called Niseis, and herself. The three Niseis are Japanese-English bilinguals and Nishimura was a Japanese native-speaker.

Through her analysis of the Niseis' behavior of switching between Japanese and English, she found three different "varieties" of the two languages. One called the “basically English variety" (1995a, 162) was mostly English with some Japanese thrown in, as in "So Friday, Ken, chotto [hold on there]," (165); the "basically Japanese variety" (162), was mostly Japanese with some English, as in "Ima school itteru no? [are you going to school?]" (1995b, 131); and the last one is called the "mixed variety," in which English and Japanese were mixed more evenly (1995a, 162). For instance, this could take the form of "portmanteau sentences," such as, "We bought about two pounds gurai kattekita no. [we bought about...]," which repeats elements of the sentence in each language (167). Each form of speech was used in different circumstances to different audiences. The first "variety" was the form used between the second-generation speakers themselves, the second was the form of speech used when talking to native speakers of Japanese, and the third was used when speaking to native and second-generation speakers together at the same time. Furthermore, she noted that second-generation speakers who were educated in North America treated fellow second-generation speakers who had been educated in Japan, or Kika-Nisei, the same way they treated native Japanese speakers. Finally, in the "basically Japanese variety" and the "basically English variety," she held 
that the occasional use of a word from a foreign language fit Poplack's definition of borrowing; however, the "mixed variety" involved true code-switching (Nishimura 1995b).

Nishimura arrived at this conclusion through noting the use of code-switched words in each instance and tabulating them by part of speech. This showed that Japaneseto-English code-switching in Nisei (second-generation) speech, which was the "basically Japanese variety" directed towards native speakers, mostly consisted of nouns, whereas the "mixed variety" used in audiences of both native and Nisei speakers used a much greater variety of parts of speech (134). These two different forms of language corresponded with Poplack's claims that the form of bilingualism in which only nouns were switched was borrowing, defined as the temporary use of loanwords, as opposed to the form of speech in which multiple kinds of grammatical items were switched, which Poplack identified as code-switching. In this way, Nishimura was able to demonstrate quantitatively the difference between these two different forms of speech, borrowing versus code-switching, and showed generally that code-switching, according to Poplack's definitions, was possible between languages of different word order (140-142).

Although Myers-Scotton (2006), who proposed the Matrix Language Frame Model, echoed many of Nishimura's basic claims about the possibility of code-switching between grammatically dissimilar languages, she accounted for language dominance in a different way. For instance, as stated above, she held that all bilingual discourse had a dominant or matrix language which was determined by scrupulously counting the morphemes, the units of word construction, in each clause, as opposed to merely 
examining the parts of speech in a clause or the word order of the verb as Nishimura did (Nishimura 1995b, 143). While she also acknowledged the existence of word borrowing, Myers-Scotton did not believe that it was fundamentally different from code-switching, but merely posited that it was a less complicated version of the same phenomenon (1993, $163)$.

Critics of the two scholars tended to emphasize this disparity. Boeschoten (1998) criticized Nishimura's studies, stating that Nishimura does not clearly define what the three varieties are, whereas Myers-Scotton appealed to a unit level smaller than the individual word, or the morpheme. This criticism is justified given the information above, since Nishimura's distinction between code-switching and borrowing denies the existence of a dominant language and is largely statistical, while Myers-Scotton's definition relies on a rigorous morpheme count. Pointing to the difference between Nishimura's work and Myers-Scotton's, Bentahila and Davies (1998) have pointed out that Nishimura does not see code-switching as requiring a dominant language to begin with, whereas Myers-Scotton claims that it is necessary and always possible to identify a dominant language.

In spite of the differences between Myers-Scotton and Nishimura in terms of dominant language, both researchers acknowledged the existence of different levels of bilingual speech and classified them according to the proportion of each language contained within. Also, they both recognized the most basic form of bilingual language as borrowing, in which only single words from the second language are used, as opposed to 
a level of greater variety, which Nishimura called the "mixed variety" and Myers-Scotton called "unmarked CS [code-switching]" $(1993,13)$.

\subsection{The Role of Code-switching in Language Contact}

The many agreements between Nishimura and Myers-Scotton make it possible to discern a handful of common principles for the study of code-switching as it relates to the development of various forms of bilingualism. The nearest analogue to mixed speech found in Myers-Scotton $(1993,13)$ is what she refers to as "unmarked CS (codeswitching)." According to her account, unmarked CS “is characterized by a great deal of switching" and "is intended to index simultaneous identities," or appeal to speakers of both languages equally, a trait which Nishimura explicitly attributes to the "mixed variety" (1995a, 166-167).

Similarly, Myers-Scotton also recognized differences in the degree to which certain kinds of words, or rather morphemes, were used in code-switching depending on the cultural assimilation of the bilingual speakers. According to her, this process of using both languages starts when the speakers of one language start borrowing "content morphemes," or morphemes that convey meaning, from another language. In the next step, the bilinguals begin to choose their second language as the new matrix language for most of their conversations, based on "socio-political prestige," a process she calls a "turnover." Soon after this point, the new matrix language takes over, and the original language is reduced to the occasionally borrowed language, which eventually is no longer spoken $(1993,227-228)$. 
In the case of Myers-Scotton's general account of language contact, these degrees of language combination form a clear line of development or change in which the first language is eventually replaced by the second language. In other words, these varying degrees of bilingual speech can also be used as a measurable metric for determining the frequency of use of the first language against that of the second language. Boeschoten (1998), a critic of Myers-Scotton, also held that there was a connection between language change and code-switching, although he saw the phenomenon as more immediate, instead of spread over multiple generations.

In this context, Nishimura's division of Japanese-English bilingual speech into three "varieties" based on the proportion of English to Japanese is especially interesting. Myers-Scotton even directly cited Nishimura regarding these divisions, holding that the Japanese-Canadians in her studies were only a couple steps away from the exclusive use of English (1993, 214). Nishimura herself saw this distinction of speech as unique to the second-generation speakers she was researching at the time. She in turn related this to the Japanese-Canadians' relationship with both Japan and Canada, as well as their socioeconomic status, holding that greater assimilation meant disuse of their original first language (Nishimura 1995a). In other words, both researchers acknowledged that the basic thrust of this process is the replacement of the original first language.

However, there are some additional concerns that throw some doubt on this conclusion. As a result of their bicultural identity, these Japanese-Canadians had undergone great political strife in Canada, in many cases losing their homes as a result (Nishimura, 1995a). The Nisei had been stripped of their communal identity and did not 
have the same political security that a less persecuted linguistic group might have. Therefore, it remains a question as to how and when Nishimura's prediction holds true, and in particular, whether the societal or political situation might completely change this in favor of the minority language, as Woolard (1989) showed in the case of Catalonia. Therefore, it is worth examining whether Japanese-English speakers whose communities did not undergo the breakup of their neighborhoods would stop using Japanese as quickly as the group studied by Nishimura.

In the following study, I make no attempt to prove the existence of a matrix language as a universal feature of code-switched conversation, or to try to pin down the precise difference between the use of loanwords and code-switching. These questions, as seen in the disagreements between Poplack, Nishimura and Myers-Scotton, have not been adequately determined in the field of linguistics and will distract from the purpose of this research. Furthermore, rather than present an account of the language ideology of the participants, I will conduct a brief survey of the participants' perceived attitudes towards English and Japanese. Following the methods utilized by Nishimura (1995b) and MyersScotton (2006), I distinguish and compare the use of different forms of bilingualism by different groups in history quantitatively by the use of code-switching in conversation, especially among Japanese-English heritage speakers in North America.

\subsection{Research Questions}

While Nishimura examined code-switching produced by speakers whose families arrived prior to 1940, this study focuses on the Japanese-Americans whose families arrived after this time, whom I henceforth call "postwar speakers." By examining this 
group, it is possible to see whether Nishimura's claim that bilingual speakers rapidly lose their less dominant language applies only to the specific group that she studied or whether it applies to other North-American Japanese-English speaking communities.

In particular, it is worth examining Nishimura's claim that speakers of the secondgeneration use a "mixed variety," defined as intra-sentential code-switching with overlap between two grammars (1995b, 139). If Myers-Scotton's claim that bilingual speakers will use different proportions of each language depending on the level of influence they receive from society is true, it remains to be seen whether the speech of the earlier Japanese-Canadians and those of postwar speakers will be grammatically different.

To investigate these issues, I posited the following research questions:

1. What is the dominant language within the discourse used by postwar speakers, if there is one? If it varies, what are the conditions that make it vary?

2. What grammatical items do postwar speakers use when they code-switch? If they use different features from the group studied by Nishimura, how do the speakers differ?

3. In particular, what variety of code-switching is used by the second generation of postwar speakers when speaking to native speakers and fellow second-generation heritage speakers? Is their speech closer to the "mixed variety" or borrowing as defined by Nishimura? If they act similarly to Nishimura's group, how do they compare to older or younger generations?

4. What attitude do postwar speakers self-report towards the two languages that they speak? 


\section{Chapter 3}

\section{Methodology}

In this section, I lay down the central questions which I attempt to answer in this study, and the process I used to resolve these questions. Next, I give a brief overview of the participants and the procedure that I used while conducting data collection. Finally, I explain my analytical process before giving the details of my data analysis.

\subsection{Research Design}

As I reviewed the previous research on code-switching, I laid out the following research questions:

1. What is the dominant language, within the discourse used by postwar speakers, if there is one? If it varies, what are the conditions that make it vary?

2. What grammatical items do postwar speakers use when they code-switch? If they use different features from the group studied by Nishimura, how do the speakers differ?

3. In particular, what variety of code-switching is used by the second generation of postwar speakers when speaking to native speakers and fellow second-generation heritage speakers? Is their speech closer to the "mixed variety" or borrowing as defined by Nishimura? If they act similarly to Nishimura's group, how do they compare to older or younger generations?

4. What attitude do postwar speakers self-report towards the two languages that they speak? 
To answer these research questions, I collected and analyzed speech data of conversations from three groups of Japanese-English postwar speakers to determine a dominant language and examine types of code-switching and their natures. Each group was composed of a total of three members, one Japanese native speaker and two heritage speakers who were mostly educated in American English. The families of all the heritage speakers educated in American English came to the United States after World War II. In addition to the conversation data, I interviewed each participant to tap into their attitudes toward Japanese and English.

\subsection{Participants}

For this study, I recruited the participants through family connections and references through connections with these friends over social media. The participants I contacted were generous and often referred me to others they knew as well, thus building the groups that I eventually used for the study itself. The two contacts from which the majority of respondents were introduced to me were respectively part of the nationwide network of Hafu Japanese Americans and the Japanese-American community living on the West Coast.

In Nishimura's study, there were clear differences between first and second generations. However, the speakers from postwar families in this study tend to come from a continuum of varying degrees of education in Japan or in the United States. Table 1 shows each participant's key profile. The age is approximate, by decade, and the participants are considered native if they have completed junior high school in Japan. This is in comparison to their status as second-generation, which is only checked if they 
were born in the U.S. With respect to education, only years of primary and secondary schooling past kindergarten are counted, starting from first grade. The names are all pseudonyms and reflect their status as native speakers only with respect to this study.

Table 1: Participant data

\begin{tabular}{|l|l|l|l|l|l|l|}
\hline Group & Participants & $\begin{array}{l}\text { Native } \\
\text { Japanese }\end{array}$ & Gender & $\begin{array}{l}\text { Japanese } \\
\text { Education }\end{array}$ & $\begin{array}{l}\text { Second } \\
\text { Generation }\end{array}$ & Age \\
\hline 1 & Noriko & Y & F & 9 & N & 50 \\
\hline 1 & Mary & N & F & 1 & N & 50 \\
\hline 1 & Diane & N & F & $>1$ & N & 50 \\
\hline 2 & Yumiko & Y & F & complete & N & 50 \\
\hline 2 & Samuel & N & M & 2 & N & 50 \\
\hline 3 & Hannah & N & F & $>1$ & N & 30 \\
\hline 3 & Lisa & N & F & $>1$ & Y & 20 \\
\hline 3 & Katherine & N & F & 0 & Y & 20 \\
\hline
\end{tabular}

Many of these postwar speakers were born in Japan, but spent very little of their childhood education in Japan, moving to America and being forced to adapt to the American school system at an early age. Following Nishimura's claim that the secondgeneration speakers in her study acted similarly towards native speakers and Americanborn Nisei who were educated in Japan, or Kika-Nisei (1995b), this study drew a distinction between native speakers and heritage speakers who were primarily enculturated in America on the basis of length of education in each country. For the 
purposes of this study, this dividing line is drawn at the completion of Japanese middle school, or the equivalent of ninth grade in the current U.S. educational system. Noriko, Yumiko, and Shizuko have completed an education in Japan up to this point, so they are considered full native Japanese speakers, and they will be referred to as such. None of the others have spent more than three years in the Japanese school system, so they are referred to as heritage speakers.

The speakers who are listed as having less than one year of education in Japan are those who attended but did not complete first grade in Japan, such as Hannah, or those who attended classes in Japan that were not part of their regular schooling, such as Lisa and Diane. Lisa attended school during her summer visits in Japan through the fifth grade, so the actual amount of time she spent in Japanese school may be greater than a year. Furthermore, she spent a year attending international middle school in Japan. However, because she did not fully complete any year in the Japanese school system, her education will be listed as less than a year. Similarly, Diane attended extracurricular courses in dance and music in Japanese while attending an English-speaking school on a military base through second grade. Since these were not part of her regular schooling, she will also be listed as having attended school in Japan for less than a year.

Another difference between Nishimura's study and this study is the fact that many of the postwar speakers describe themselves as Hafu or half-Japanese English and Japanese speakers, oftentimes with connections to the military in some form. This is a self-applied cultural label with its own identity; not all of the speakers who report they are half-Japanese identify as Hafu. Also, Lisa and Shizuko from Group 3 live what I call 
an expatriate lifestyle, meaning that they occasionally move from America back to houses owned by their family in Japan, often staying for months at a time. This manner of life is present to some degree in nearly all the participants, who either moved to the U.S., or who have spent some time living in Japan. Among all nine participants, only Katherine has lived her entire life in America, aside from occasional visits to Japan as a tourist or visiting her husband's family. The relevance of these identities towards the speech and the language attitudes of the participants will be discussed later in this study.

Group 1 consisted of three women in their 50's who referred to themselves primarily as Hafu. All three of these speakers were born and spent their earliest childhood in Japan, but have had different degrees of exposure to Japanese culture. Noriko, who fit the group's role as someone most exposed to Japanese culture, graduated from conventional middle school in Japan before moving with her family to the U.S., where she attended high school. The other two participants, Mary and Diane, though born in Japan, moved to the U.S. at a much earlier age. All three women had mutual connections through a dedicated Facebook page devoted to Hafu speakers and conversed with each other frequently. Mary was the only family friend among the participants and the others were connections of hers.

The second group consisted of two Hafu speakers and a non-Hafu parent of one of the participants. Samuel was a Hafu speaker in his 50's, Hannah was a Hafu speaker in her 30's, and Hannah's mother, Yumiko, was in her 50's. Similar to Group 1, none of the participants were born in the U.S. Yumiko moved to the U.S. as a married adult with her child, Hannah, who did not go beyond the first grade in Japanese school. Samuel arrived 
in the U.S. at a much later time, around the age of thirteen, but attended an Englishspeaking school on the military base on which he grew up. Although he had some exposure to the conventional Japanese school system, he did not go beyond the second grade before transferring out. The two Hafu speakers, Samuel and Hannah, also had mutual connections to the Facebook group mentioned above. They were introduced to me through the mediation of Noriko from Group 1.

In Group 3, one native speaker, Shizuko, in her 70's, is paired with two young second-generation heritage speakers, Lisa and Katherine, who were both in their 20's. Contrary to the participants in Group 1 and Group 2, Lisa and Katherine were born in the U.S. although each spent different amounts in Japan later in life. Lisa was born in the U.S. but spent some of her childhood in Japan, going back and forth between the educational systems of each country. She is also half-Japanese, but never referred to herself as Hafu, which is the unique word used by the older half-Japanese women in Group 1. The other speaker, Katherine, did not live in Japan for any extended period of time at all, but only visited Japan for short periods at a time. She is the only secondgeneration heritage speaker in this study who is not also half-Japanese. This group was also the most disparate of the three conversation groups, since all the participants were unfamiliar with each other, though the two second-generation women had mutual connections to some extent. Shizuko was a family friend of mine, while the other two were connections of another family friend.

\subsection{Data Collection}


As mentioned in Research Design, I collected two types of data, the original speech from three conversations and responses in the post-conversation interviews. After participants responded to my call for volunteers, I scheduled the conversation sessions through email, and I hosted the Zoom gatherings, setting the time for the conversations through the invitation system provided by Portland State University. Similarly, once the group conversations were over, I contacted each participant individually via email to schedule the post-conversation interview, which I also administered via Zoom.

Given that the participants oftentimes were mostly connected through social media and did not live in very close proximity to each other, and under the socially distant conditions imposed by COVID-19, the recording apparatus consisted of a computer, as used in a mass internet call. The main instrument used was the recording function of an internet call program, in this case Zoom, supplemented with a physical voice recorder for backup.

\subsubsection{Group Conversations}

When the participants of each group logged onto the scheduled Zoom meeting, they were given a prompt of the questions listed below, written both in Japanese and English.

- What have been your experiences as a bilingual speaker in America?

- Which current events in America and the world are of interest to you?

The participants in each group were then left to discuss the topics freely with minimal input from the researcher, who only explained the questions and format of the 
study in both English and Japanese, so as not to determine any specific language for the conversation. In one instance, during the second group conversation, the researcher intervened to help determine whether the call quality was sufficient to continue research, and immediately left after it was decided to not impede conversation. Except for this one instance, the researcher did not participate in any call, but rather hosted the call without sound or a live video feed, and stood by for the sake of answering questions about conversation protocol if the participants had any. After thirty minutes, the researcher returned as an active participant in order to stop the conversation. Once the data was recorded, it was saved in a password-protected file folder on the researcher's computer.

\subsubsection{The Interviews}

Once the initial group conversations had taken place, the researcher administered the post-conversation interview by himself, in a one-on-one format with each of the participants. I directly asked the participants the following questions:

- "What are your positive experiences speaking Japanese in America, if any?"

- "What experiences have made you feel like an outsider in America, if any?"

- "Are you more comfortable speaking Japanese or English and why?"

- "Which language do you speak more with those who are close to you and why?"

- "Do you feel that Japanese or English is a more cultured language, and what makes you feel this way?" 
- "Do you feel that you are able to retain your use of Japanese? What experiences allow you to do this?"

These interviews lasted approximately fifteen to twenty minutes on average, and were conducted in either Japanese or English. They were not given the questions ahead of time in order to hear their initial impressions. In only one instance, I translated the questions into Japanese at the request of Yumiko, one of the native speakers, but on the whole, the questions were asked as they were written in English. The data for these interviews were stored with the same care as the initial conversations, but were not transcribed. This also provided an opportunity to share the conclusions of the researcher based on their earlier responses in the interview, and to ask for their feedback and insights as to their behavior.

\subsection{Analysis of Data}

As to the actual analysis of the data, first, it is necessary to determine what the dominant language of each group is within the discourse used by postwar speakers. Then, it is possible to infer whether the second generation of Japanese-Americans whose parents arrived after World War II will use grammatically "mixed" speech, in which the use of two languages is equally distributed, when speaking to native speakers and fellow heritage speakers of their generation. However, if the distinction between the group studied here and that studied by Nishimura (1995b) is not dissimilar according to the standards that she developed, it is still important to determine whether the heritage speakers differ in more subtle ways, or focus on different grammatical features. Lastly, for the sake of determining the nature of the language attitudes at work, it is also 
worthwhile to determine whether the speakers self-report a high or low opinion of Japanese compared to English.

This research is conducted primarily according to the matrix language frame methodology of Myers-Scotton (MLF), according to the basic concepts which she and Nishimura both share in common. Also, for the sake of comparison, all the participants in the entire conversation are analyzed, and not merely the heritage speakers. The goal of the study is to determine the nature of the code-switches involved in each set of participants. This may be determined by first describing the framework in which the switches occur, such as the dominant language, and then taking appropriate samples from the transcript that clearly show deviations from the dominant language.

Following Myers-Scotton's method, the dominant language of a conversation is determined by the number of morphemes in a given language; thus, whichever of the two languages has a greater number of morphemes is the matrix language of the conversation. Morpheme, a minimal meaningful linguistic unit, is a more objectively defined unit of analysis than word count since what is considered a word can vary according to context.

In the English language, the clearest divisions between morphemes can be seen in the divisions between word stems and their endings, such as those which indicate tense and person:

Tense (past): jump-ed [2 morphemes]

Person (third-person): [(he) jump-s, 2 morphemes] 
Japanese, an agglutinative language, tends to include more morphemes in each individual word than English, particularly in verbs. As opposed to the previous example in English, the form of verbs is not affected by person. Also unlike English, parts of speech such as verbs and adjectives can be conjugated for voice and for other features:

Past: Home-ta [verb ("to praise"), 2 morphemes]

Past Passive: Home-rare-ta ("to be praised," 3 morphemes)

Similar divisions between morphemes in Japanese that do not occur in English also occur between adjectives and their endings, such as taka-i, and in certain noun forms, such as "odor-i-te" (Tsujimura 2007, p. 137, italics added). Therefore, slightly different practices need to be followed for each language. For the sake of counting morphemes in either language, for the purpose of this study, I rely on the methodology used by Tsujimura (2007) for counting morphemes in Japanese, and on O'Grady and de Guzman (2017) for English.

For example, when evaluating the dominant language of the beginning of the conversation in Group 1, I identified morphemes for English and Japanese parts of each participant's utterances. In the following excerpt and for the rest of the paper, all words that are not of the dominant language will be italicized.

(1) Excerpt: Diane's first utterance [Group 1]

1. Diane: *Well, first of all, hajime/mashi/te, Noriko/san

$\begin{array}{lllll}\text { English } & 1 & 1 & 1 & 1\end{array}$ 
Japanese

$$
\begin{array}{llllll}
1 & 1 & 1 & 1 & 1
\end{array}
$$

Note: 'hajimemashite, Noriko-san' means 'It is nice to meet you, Mrs. Noriko.'

Hesitations, indicated by an asterisk, such as "um," or "anoo" were not included in the count. Also, lack of an explicit subject, a common feature of many Japanese sentences, and other more discourse-related grammatical features will remain left out and will not affect the morpheme count, following Tsujimura (2007). The words that consist of a single morpheme are left unmarked, while those which consist of multiple morphemes are clearly divided into those morphemes by slashes. These morphemes are then tallied up, and compared against each other in order to determine the matrix language. In this case, there are five Japanese morphemes as opposed to four English morphemes, so the dominant language of this clause can be considered Japanese, in which the words "[w]ell" and "first of all" can be thought of as an adverbial phrase and a clitic that are code-switched. This is also confirmed by the fact that the main predicate of the sentence is Japanese.

Following the lead of Myers-Scotton (1993), I excerpted the first minute from the beginning of each group's conversation, transcribed the speech, and counted English and Japanese morphemes to determine the initial dominant language in each group's conversation. This initial dominant language then formed a standard on which to base the rest of the analysis of the conversation. Once the dominant language was identified, it was possible to determine which words belonged to the secondary language when codeswitching occurred. This could take the form of switches between clauses that are entirely in one or the other language, also called inter-sentential code-switching. For instance, a 
complete clause may occur entirely in Japanese, which is in turn followed by a clause entirely in English. This study did not attempt to account for this form of switching. Rather, this study focused on intra-sentential code-switching, in which each clause contains words or grammar of both languages. Each switch that occurred in the middle of a clause was tallied and listed by the part of speech used.

Once the initial dominant language was established, there were normally very few instances longer than a few sentences at a time in which the secondary language was primarily used. Those cases when the secondary language was used more extensively and seemed to be the primary language were in noted in the transcript. However, these instances were only considered in the analysis when the sentences themselves contained intra-sentential code-switching from the temporary dominant language to the now secondary one. The change of dominant language itself was not analyzed, since this research is solely concerned with code-switching at the level of words or phrases.

Given the disagreement between Nishimura and Myers-Scotton, it was necessary to refine the meaning of "mixed" speech. Following Nishimura's terminology (1995b), when a given clause is evenly distributed between Japanese and English, such that "no one basic language can be identified," it is then counted as "mixed." If, however, the use of second-language elements consisted only of single words, it was considered "borrowing" and received less priority (125). In this way, she saw the "mixed variety" as more fully code-switching than the use of borrowed words, though this study will call both forms code-switching for the sake of simplicity. In order to become usable as a tool for comparing code-switches, it was necessary to extend the range of "mixed" speech to 
include situations in which more than one foreign word is used in a clause, but less than equal amounts.

In the context of her paper, Nishimura usually considers all code-switching involving nouns alone, as opposed to including other parts of speech, as borrowing (134). She further states that the speech she labeled as "mixed" had a greater variety of parts of speech that were switched, such as adjectives, particles, verbs, and prepositional phrases, oftentimes interspersed between words in the other language, as in, "One algebra question $o$ mark- shite" (135). In these cases, very often the predicates would be affected. In extreme cases, the "mixed variety" can also include "portmanteau sentences," in which two sentences from each language are joined together as one (139). Therefore, any sentence environment in which multiple different parts of speech besides nouns are switched will count as some degree of "mixed" speech, culminating in portmanteau sentences as the most complete form of "mixed" speech. The hierarchy of clauses with various degrees of code-switching as it approaches the "mixed variety" will be as follows, starting from lowest to highest: clauses with only borrowed nouns, clauses with borrowed parts of speech that are not nouns, use of multiple different parts of speech in the same clause, especially in predicates, and portmanteau sentences. Therefore, rather than relying exclusively on morpheme-level analysis, this study will rely on the diversity of the parts of speech that are at play in each clause.

The initial goal, then, is to discover whether the postwar Japanese-American heritage speakers considered in this study speak a language that resembles the "mixed variety" of the second-generation Japanese-Canadian group studied by Nishimura. 
Although according to the new definitions, any use of parts of speech other than nouns can be considered "mixed," it will be the last two categories that are especially pertinent, i.e. clauses with multiple parts of speech in the secondary language and portmanteau sentences. This is because even single words can be considered as borrowed whether they be nouns or not, as Nishimura concludes in her paper (140).

Table 2: Subdivisions of code-switching

\begin{tabular}{|l|l|}
\hline \multicolumn{2}{|c|}{ Forms of Code-switching } \\
\hline \multirow{2}{*}{2.} & Inter-sentential Code-switching (not considered) \\
\hline \multirow{2}{*}{ Borrowing } & Intra-sentential Code-switching \\
\cline { 2 - 3 } & b. other parts of speech \\
\hline \multirow{2}{*}{ Mixed } & c. multiple parts of speech in one clause \\
\cline { 2 - 2 } Speech & d. portmanteau sentences \\
\hline
\end{tabular}

The parts of speech that this study focuses on are slightly different from those in Nishimura's study. First, instead of making a separate category for nouns and noun phrases, as did Nishimura (1995b, 134), these are both considered only nouns. Therefore, parts of speech that are used to connect words into phrases, such as conjunctions and prepositions, are not counted as separate unless they are used by themselves or in a prepositional phrase, such as "under the bridge." As well, instead of referring to words with conversational emphasis such as maa (well) or deshou (isn't it) and their English equivalents as "discourse markers" as does Nishimura, the study calls these "clitics," and follows her lead in not including them as words with great grammatical value when 
evaluating for mixed speech $(128,129)$. Similarly, repetitions of entire phrases and quotations are considered single words, and the different parts of speech contained inside them are not considered as contributing to mixed speech, unless they are combined with other words to make complex clauses.

Furthermore, there is one word class in Japanese that calls for an explanation. According to Tsujimura $(2007,125)$ words such as "kirei," which ordinarily need "na" in order to modify nouns, are referred to as "adjectival nouns" and stand apart from true nouns or adjectives. However, in the system used by Jorden and Noda $(1987,127)$, these are called "na-nominals" and grouped together with words that would ordinarily be considered nouns in the "nominal" class. "Adjectivals" are defined as those words that have endings such as $-i$ and their negative form is $-k u$ nai, whereas "na-nominals" have endings such as $d a$ and their negative form is ja nai. This study will adopt the Jorden and Noda's approach to defining word classes, and the three major categories of predicate types in Japanese will also follow Jorden and Noda's system: verbals, adjectivals, and nominals (52).

When no clauses that could not be placed in the two "mixed" speech categories were produced, the study identified the parts of speech from the second language contained in these clauses, and compared them with the variety of parts of speech used in similar conversations from Nishimura's study (1995b). This, in turn, was used to determine whether the participants involved used different proportions of each language in their speech. 
With regard to the interview data, I compared the participants' use of English or Japanese with their language attitudes to see if there is a contradiction between their linguistic behavior and their beliefs and attitudes. The self-reported behavior in the postinterview is matched up against the actual use of code switches in the conversation data. This was useful, but not conclusively so, for determining the possible motives and language attitudes of the speakers. In this way, especially if there were contradictions between stated belief and practice, the results would suggest what factors, such as language identity or social needs, might play a role in the heritage speakers' retention of their heritage language. 


\section{Chapter 4}

\section{Data Analysis}

In this section, I will present the data collected from postwar speakers, with an initial analysis of what it contains, based on the approach described above. In particular, this section will focus on the first three research questions presented in this study. I begin by determining the initial dominant language of each conversation, followed by discussions of variations from these initial languages. This will answer the question of which languages are preferred by heritage speakers from postwar generations when they speak to native speakers. Next, these variations will then be compared and contrasted to the three forms of code-switching as detailed by Nishimura, which in turn will show what parts of speech are code-switched by postwar speakers. Lastly, this section will also address the language of the second-generation heritage speakers specifically, describing their dominant language and the kind of code-switching they adopt when speaking in group that includes a native speaker.

\subsection{Dominant Language}

After transcribing approximately the first minute of each group conversation, I tallied morphemes in the speech data from each language. Table 3 shows the morpheme tally in each group.

Table 3: Morphemes of each group conversation

\begin{tabular}{|l|l|l|l|l|}
\hline Morpheme Tally & JPN morphemes & ENG morphemes & Total & matrix language \\
\hline Group 1 & $8(5 \%)$ & $154(95 \%)$ & 162 & E \\
\hline
\end{tabular}




\begin{tabular}{|l|l|l|l|l|}
\hline Group 2 & $84(87.5 \%)$ & $12(12.5 \%)$ & 96 & J \\
\hline Group 3 & $21(15 \%)$ & $123(85 \%)$ & 144 & E \\
\hline
\end{tabular}

For the purposes of this study, I have decided to form a separate group for words that are unique to the Hafu speakers, In fact, the word "Hafu" itself is in this new group. It is pronounced in a combination of English and Japanese phonology, as opposed to the Japanese loanword haafu, which also refers to those are half-Japanese. Since these words are less than $1 \%$ of the total morphemes, this study will not focus on these words in the analysis, though it will count them as part of the total words.

In the first minute of the first group conversation, the conversation is overwhelmingly in English, at more than 90\%, but Japanese does remain a significant, if small, portion of the morphemes used by the postwar speakers. In contrast, the dominant language in the first minute of the second group conversation is Japanese. Other than the first sentence by which the speaker Samuel begins the conversation, practically every word in this conversation is in Japanese, except for English borrowings, which are mostly treated as Japanese loanwords. However, words such as kompyuuta (computer) and keeburu (cable) from the first minute of the dialogue are both already established as loanwords from English. Since there is no modern day Japanese native word equivalent for these loanwords, they will not be considered as code-switching.

Contrary to my initial expectations, the third group conversation ended up being almost entirely in English. It is especially interesting since the native speaker Shizuko and one of the young second-generation participants Lisa, appeared to be planning to 
speak to each other in Japanese, when they were interrupted by the other secondgeneration speaker, Katherine, who asked to be able to speak English on the grounds that she was not confident enough in her proficiency to speak Japanese to outsiders. What might have been a conversation with significantly more Japanese in it was curtailed in order to fit the comfort of a member who claimed to be less proficient, and who claimed to not want to risk offending the other speakers in Japanese. However, switches in many individual word categories continued anyway, mostly by the two more confident speakers in the conversation.

Furthermore, the conversations rarely deviated from the initial dominant language established in the first minute of recorded data; when they did, the secondary language assumed the role of the temporary dominant language before the speakers reverted back to the previous pattern. Though Samuel from Group 2 used occasional sentences in English in the midst of a mostly Japanese conversation, both Group 2 and Group 3 were almost totally uniform in all participants using the same dominant language. Also noteworthy were a few instances of a temporary switch to Japanese as the dominant language in Group 1, which occurred in small, concentrated sections, after which the dominant language reverted back to English. Since this study does not examine intersentential code-switching, the passages which are uniformly in Japanese are not considered in the current analysis, though these passages were noted in the transcript below.

4.2. Variants of Code-switching used by Postwar Speakers 
The following table presents the token counts of the three variants of codeswitching: English-to-Japanese, Japanese-to-English, and "mixed" speech by member and group. The study will then further compare them to the "varieties" described by Nishimura (1995b).

Table 4: Total of switches per participant by group:

\begin{tabular}{|l|l|l|l|l|l|}
\hline Group & Participant & ENG-JP & JP-ENG & MIX & Total \\
\hline 1 & Noriko & 11 & 5 & 2 & 18 \\
\hline 1 & Mary & 9 & 4 & 3 & 16 \\
\hline 1 & Diane & 4 & 2 & 0 & 6 \\
\hline 1 & Group Total & 24 & 11 & 5 & 40 \\
\hline 2 & Yumiko & 0 & 2 & 0 & 2 \\
\hline 2 & Samuel & 0 & 11 & 0 & 11 \\
\hline 2 & Hannah & 0 & 8 & 0 & 8 \\
\hline 2 & Group Total & 0 & 21 & 0 & 21 \\
\hline 3 & Shizuko & 10 & 0 & 0 & 10 \\
\hline 3 & Lisa & 9 & 0 & 0 & 9 \\
\hline 3 & Katherine & 4 & 0 & 0 & 4 \\
\hline & Group Total & 23 & 0 & 0 & 23 \\
\hline & & & & & \\
\hline
\end{tabular}


In the conversation of Group 1, all of the three variants of code-switching are observed, and two of three members used all three variants. Of switches from Japanese to English, the native speaker Noriko took up the largest share, producing 5 code-switches that comprised $45 \%$ of all 11 Japanese-to-English switches in the conversation. However, both of the Japanese-American heritage speakers, Mary and Diane, used them as well, contributing 4 and 2 switches respectively, or approximately $36 \%$ and $18 \%$. However, when it came to "mixed" speech Mary was the foremost user, producing 3 out of 5 instances, or $60 \%$, though Noriko produced the other 2 , or $40 \%$. This is also true when taken as a percentage of their personal totals; “mixed” clauses equaled 19\% of Mary’s total code-switches, as opposed to $11 \%$ of Noriko's. Therefore, native speakers can use "mixed" speech, though it is more properly attributed to heritage speakers who have had earlier exposure to English. Finally, all three of the participants used English-to-Japanese code-switching. Noriko produced 11 , or $46 \%$, Mary produced 9 , or $38 \%$, and Diane produced 4 , or $17 \%$ of the 24 instances.

Although none of the postwar speakers involved were born in the U.S., and the amount of time the speakers spent being educated in Japan differs by less than ten years, there are many similarities between the conversation of Group 1 and the conversations involving Nisei and native speakers featured in Nishimura's study. Just as she showed in the case of the Japanese-Canadians, the speakers from Group 1 switched from English to Japanese, Japanese to English, and at times used structures that had elements of each language. Therefore, Group 1 is the closest of all the groups in the study to the data from Nishimura's Nisei. 
Contrary to Group 1, the other two groups did not produce mixed speech at all. In Group 2, Yumiko, Samuel, and Hannah produced 2, 11, and 8 Japanese-to-English codeswitches respectively, but no English-to-Japanese switches at all, while Shizuko, Lisa, and Katherine from Group 3 produced 10, 9, and 4 English-to-Japanese code-switches and nothing more. Therefore, while this confirms the existence of the primarily English and primarily Japanese varieties of code-switched speech as described above by Nishimura, it also shows behavior that does not match with the first group, though their respective contexts should have been similar.

As the researcher initially thought, the two Japanese-American heritage speakers in Group 3, who were second-generation, did not use "mixed" speech when in conversation with each other, as did the Hafu women from Group 1. They may have been hindered by their unfamiliarity, but it seems more likely that the conversation would have been carried out mostly in Japanese, like the second group conversation, if Katherine had not intervened in favor of English. Therefore, it seems likely that the younger speakers in this study incline towards speaking either one language or the other, though they permit the use of occasional switches. However, the almost exclusive use of English was not expected by the researcher, who originally believed that the use of Japanese was widespread even among those who did not live in Japan for an extended period of time.

\subsection{Parts of Speech}

The variants of code-switching other than the "mixed variety" consist of borrowing that switches parts of speech from one language to another. Table 5 shows the 
token counts of different parts of speech observed in the code-switching from English to Japanese by individual members and by groups. Since there was no English-to-Japanese code-switching as shown in Table 5, Group 2 is not included in this table.

Table 5: English-to-Japanese code-switches:

\begin{tabular}{|c|c|c|c|c|c|c|c|}
\hline Group & Participant & Nominal & Clitic & Quotation & Repetition & Adjectival & Total \\
\hline 1 & Noriko & 4 & 6 & 1 & 0 & 0 & 11 \\
\hline 1 & Mary & 1 & 0 & 7 & 1 & 0 & 9 \\
\hline 1 & Diane & 1 & 0 & 2 & 1 & 0 & 4 \\
\hline 1 & Total & 6 & 6 & 10 & 2 & 0 & 24 \\
\hline 3 & Shizuko & 6 & 0 & 3 & 0 & 1 & 10 \\
\hline 3 & Lisa & 7 & 0 & 2 & 0 & 0 & 9 \\
\hline 3 & Katherine & 4 & 0 & 0 & 0 & 0 & 4 \\
\hline 3 & Total & 17 & 0 & 5 & 0 & 1 & 23 \\
\hline All & Total & 23 & 6 & 15 & 2 & 1 & 47 \\
\hline
\end{tabular}

Shown together, the two groups exhibit a relatively wide range of code-switching in terms of parts of speech ranging from nominals and adjectivals to more discourserelated parts of speech, such as clitics and repetitions. Nominals are the part of speech used most consistently by all the participants, who each use them at least once, followed 
by quotations, which only Katherine does not use. Group 3 has the largest percentage of nominal use to code-switches overall, totaling 17 out of 23 , or $74 \%$ of all their codeswitches, as compared to Group 1, which only switches nominals $25 \%$ of the time. In contrast, Group 1 had a much higher rate of using discourse-related parts of speech. The clitics, repetitions, and quotations used by Group 1 added together total 18 out of 24 uses, or $75 \%$, as opposed to a significantly lower 5 out of 23 , or $22 \%$, for Group 3 .

This presents an interesting contrast to the results of Nishimura's earlier study (1995b, 137). In her version, the variety of code-switching that contains "mixed" speech, which is mostly reproduced in this study by Group 1, had a very wide range of parts of speech in English-to-Japanese code-switching, including prepositional phrases, case particles, and conjunctions, which do not show up in this study. This does not include words that were considered to be adverbs and predicate adjectives by Nishimura, which are largely subsumed under the category of nominals in this paper's approach. Therefore, even given the consolidation of parts of speech in this paper, there is slightly less variety in the "mixed" speech spoken by Group 1 than in the original "mixed variety" spoken by the Japanese-Canadians of Nishimura's study (1995b).

However, in the "basically English variety" of code-switching spoken by Group 3 , there are actually more parts of speech used than in the speech of the JapaneseCanadians studied by Nishimura (1995b, 133). Rather than stick with idioms such as natchuu no and chotto, as opposed to regular parts of speech, these postwar JapaneseAmerican heritage speakers, along with the native speaker assigned to them, tended to use nominals and adjectivals as well. This may suggest that when postwar speakers 
primarily use English, they also code-switch to Japanese much more than in earlier generations. However, since the Japanese-Canadians in Nishimura's study used the "mixed variety" in a similar situation, it does not show that the postwar JapaneseAmericans use more Japanese in comparison to earlier studies.

Table 6 presents the token counts of Japanese to English code-switching in terms of parts of speech. Since Group 3 did not produce any such code-switches, they will not be included in this table. Therefore, the following discussion will focus exclusively on Groups 1 and 2.

Table 6: Japanese-to-English code-switches

\begin{tabular}{|l|l|l|l|l|l|l|}
\hline Group & Participant & Nouns/Nominals & Clitics & Adverbs & Quotations & Total \\
\hline 1 & Noriko & 2 & 2 & 0 & 1 & 5 \\
\hline 1 & Mary & 0 & 4 & 0 & 0 & 4 \\
\hline 1 & Diane & 0 & 1 & 1 & 0 & 2 \\
\hline 1 & Total & 2 & 7 & 1 & 1 & 11 \\
\hline 2 & Yumiko & 2 & 0 & 0 & 0 & 2 \\
\hline 2 & Samuel & 11 & 0 & 0 & 0 & 11 \\
\hline 2 & Hannah & 8 & 0 & 0 & 0 & 8 \\
\hline 2 & Total & 21 & 0 & 0 & 0 & 21 \\
\hline All & Total & 23 & 7 & 1 & 1 & 32 \\
\hline
\end{tabular}


As shown above, there is a significantly smaller diversity of parts of speech used than in the English-to-Japanese code-switching table. Here, the table is dominated almost exclusively by nominals, a staggering 23 out of 32 or $72 \%$ of all the code-switches listed. In the case of Group 2, no majority English sentences or sentences involving "mixed” speech as defined above were formed at all. As for Japanese-to-English switches, in one isolated instance, Samuel used an English adjective but conjugated it as a $n a$-nominal. In all other cases, all of the switches manifested themselves both in grammar and pronunciation as Japanese-style nominals, the form normally assumed by orthodox loanwords. In this situation, however, the borrowings were words that have not been accepted by the majority of Japanese speakers as loanwords.

These limited results largely correspond to Nishimura's description of the "basically Japanese variety" of code-switching, in which primarily nouns and adjectives are switched, as well as discourse markers, which did not appear in this case (1995b, 128). Therefore, at least in terms of the grammatical items used by the heritage speakers, this may be regarded as the same variety of speech, though there is a tendency to favor the use of Japanese.

However, though two of the heritage speakers in Group 2 had been educated both in the U.S. and in Japan, as were the members of Group 1, they preferred to speak almost entirely in Japanese. This may simply be attributable to the presence of the native speaker, who had not received her education in the U.S. Nevertheless, despite their proficiency in both languages, these two heritage speakers did not use the "mixed" speech of Group 1 in talking to each other in the conversation. Lastly, as might be 
expected, the speakers who did most of the code-switching, or borrowing in this case, are the two Japanese-American heritage speakers. The native Japanese speaker only used unusual borrowings twice in this entire dialogue.

Lastly, many of the Group 1 speakers also switch from Japanese to English, though the variety of grammatical items is much smaller than in the list for "mixed" speech from Nishimura, missing items such as prepositional phrases, conjunctions, and compound verbs made of an English word and the Japanese word "suru" or "to do" (1995b, 134). This mirrors their use of English to Japanese code-switching, which was also similarly limited. Taken together, this suggests that, aside from their use of "mixed" speech, Group 1 prefers to keep its languages separate, speaking English or Japanese more consistently than the Japanese-Canadians in Nishimura' study.

\subsection{Borrowing}

The first and most common form of code-switching in this study consists of individual phrases, was considered by Nishimura to be fundamentally similar to the loanwords that occur in ordinary speech when one language adopts the words of another. The borrowings considered in this study consist of two kinds: use of Japanese words in an English context, and use of English words in a primarily Japanese context. For the most part, these borrowed words are pronounced according to the language they originally came from; however, there are some exceptions, particularly from the conversation of Group 2, that appear to be spontaneously translated into the primary language of the sentence. 


\subsubsection{English to Japanese Borrowing}

Continuing further in the conversation, there is much borrowing of Japanese single words and phrases, as well as conversational markers as Nishimura commonly found in majority English speech. Of the three groups, only Group 1 and Group 3 produced this form of code-switching, while Group 2 exclusively produced switches that put English words in a Japanese context. The following excerpt presents an example of using nouns, in this case Japanese family terms, inserted in a sentence in English.

(2) English to Japanese nouns: ojiichan obaachan [Group 1]

1. Noriko: I'm not gonna speak the language and the family or the ojiichan obaachan, or grandmas and grandpas

they said you're American you know, speak the language.

Similarly, Group 3's code-switching patterns were those of borrowing single words from Japanese. The speech of the participants here included switches from the adjectival category as well:

(3) English to Japanese adjectivals: muzukashii kanji [Group 3]

1. Shizuko: It's so difficult for me too, to write * muzukashii kanji, correct, you know difficult choosing a correct, writing a kanji is very difficult for me too. 
The next excerpt is an example of clitics in Japanese used in the middle of an English clause. These consist of words that primarily contribute conversational emphasis.

(4) English to Japanese clitics [Group 1]

1. Noriko: But I'm sure you've probably seen a lot of like cooking, cooking channel, deshou? haven't you?

2. Mary: When you listen to the NHK, Japanese or English, they have both.

In line 1 , the word deshou is a form of the copula desu, which is normally attached to a nominal. Here, it serves much the same function as the English word "right?" would do, seeking the respondent's approval. In some cases, a phrase longer than a word in one language is repeated in another language. The next excerpt exemplifies the repetition.

(5) English to Japanese repetitions [Group 1]

1. Noriko: So Denise, Denise did you grow up in Japan?

2. Diane: Um, I moved to Southern California when I was eight, hassai no toki.

when I was eight

3. Noriko: Hassai no toki? Okay. I was * sixteen. Almost sixteen. Jyuu-gosai to jyuu When you were eight? Maybe when I was fifteen and eleven ikkagetsu kana? Yeah. 
months old

In line 2, Diane first rendered her age at the time she originally moved to the U.S. in English and immediately repeated the same content in Japanese. In this way, a heritage speaker can use relatively involved switches to other languages without using complicated grammatical structures in the course of the conversation.

\subsubsection{Japanese to English borrowing}

There are cases of borrowing from Japanese to English. Even in Group 1's conversation, in which the dominant language was English, not all switches are in an English-to-Japanese context. In fact, some are actually in majority Japanese sentences.

(6) Japanese to English clitics: 'so' [Group 1]

1. Noriko: And so group of us just get together, and its its hontou ni champon ne, its really mixed up, right

like *, you know Japanglish to ka sa, Englinese hanashite mitai na kanji, so

$$
\text { or such, [and] it's like we were speaking [Englinese] }
$$

In this case, the English word "so" used towards the end of Noriko's utterance in the excerpt is used as a clitic in a Japanese sentence environment. It does not introduce any new material, and tails off to indicate a sort of incomplete sentence. More importantly, the words "Japanglish" and "Englinese", which were presumably made on the spot, but which adopt the common "-ish" and "-ese" suffix to denote languages, 
clearly take from English morphemes and should be considered English words, in this case nouns.

In the conversation of Group 2, there did occur English words which were pronounced as if they were standardized loanwords adopted into Japanese. However, these were actually not standardized at all, and may not even be recognized by native Japanese speakers who are not familiar with the English language. The following excerpt presents such examples.

(7) Nonstandard borrowings: miritarii buratto [Group 2]

1. Samuel: Dakara, tipicaru na miritarii buratto mitai na, * seikatsu wa bokura

In that way I was a typical military brat, and the three of us siblings, would live, sankyoudai wa shita, shitenai desu ne.

or would not live, in that way.

The phrase tipicaru na miritarii no buratto in line 1 is not a phrase that would occur in Japanese, not being a concept familiar to ordinary Japanese experience. Other than the Jieitai, or self-defense forces, there is no standing Japanese army, and the experience of being a "military brat" who moves around from base to base with their parents is not as widespread an experience as it is in the U.S. Here, the English phrase "typical military brat" is being directly imported from English.

However, it is not kept as an English word with English pronunciation. Instead, it is treated as a borrowed word with Japanese pronunciation that an ordinary native 
Japanese speaker might use. "Typical" is even rendered as a nominal requiring $n a$ in order to modify another nominal phrase. It is, however, probably unique to these speakers, since Samuel and the other heritage speaker render it differently in the conversation.

(8) Additional nonstandard borrowing: miriterii [Group 2]

1. Hannah: Watashi no danna mo miriterii dakara, watashitachi wa kekko hikkoshi ga Since my husband was in the military, we would move a great deal, oookute, * ima mo moosukoshitara, * ima wa genzai Furorida ni sunderun desu and in just a little bit, although we live in Florida right now, kedo, * rai raigetsu ni wa * Cariforunia ni ano hikoshimasu. Demo, sore irai ni we're going to move to California next month. And even beyond that, mo, Tekisasu ni mo hikkoshita koto mo arimasu shi, ato ni Italia ni san nen, * we've also spent some time in Texas, as well as three years in Italy. sundeimashita.

In line 1, Hannah renders the English word "military" as miriterii while the other speaker in the earlier excerpt pronounces it miritarii. The communication does not seem to be hindered, but it is clear that there is no consensus between the two as to how this word ought to be pronounced in Japanese. Since they never changed their pronunciation to match each other, it seems likely that each pronunciation is unique to each speaker. 
Many of these words were specific to American life and referred to matters that are perhaps not commonly spoken about in contemporary Japanese society. Oftentimes these words referred to military and naval matters, which were a common fact of life to many of the Hafu speakers whom I interviewed. It seems likely that in speaking to each other, the Hafu speakers would gravitate towards using the English words, which they both knew, instead of hunting for an exact Japanese equivalent. This was the case even when the speakers were very proficient in Japanese.

\section{3 "Mixed" speech}

In the case of Group 1, not all switches fit into either form of borrowing, and some even overlap grammatically. This gives credence to the idea that this is actually closer to "mixed" speech as explained by Nishimura (1995b). This occasional merging of the two languages suggests a grammar that in some cases is an application of the grammar of one language to another, but at other times produces sentences that do not rely on the grammar of either language. Among these exceptions are quotations introduced by "mitai ni/na" and other portmanteau constructions, as seen below:

\section{(12) mitai ni [Group 1]}

1. Mary: (?) That happened a lot to me, with my relatives *, you know Mary-chan wa miss Mary is half

haafu blah blah blah, and they'll say yappari gaikokujin dakara, kurutteru yo ne, as if to say since she's a foreigner, she's acting strange isn't she? 
mitai ni...

Aside from probably intentionally humorous and idiosyncratic code-switches such as the use of English speech tropes such as "blah blah blah" in a Japanese environment in line 1 , this passage also stands for a possible portmanteau construction: the use of "mitai $n i$," meaning "like" or "as if to say" to introduce a quote in Japanese. Since there is no need for a word or grammatical item to introduce a quote in English, this may not necessarily be a portmanteau construction. However, this very feature of English also renders the need to introduce a quote unnecessary, and therefore begs the question of why the use of mitai ni is even there in the first place. For the sake of this study, this will be considered as a variety of portmanteau speech. However, there are also more obvious examples as well, including the one below:

(11) Portmanteau: like yabai tte kanji de [Group 1]

1. Noriko: Cause you know, I'm tall, I'm 5'8', so I get on the train, and people start like looking at me like up and down, deshou? And then they'll start like whispering, you right?

know in Japanese, and then I'll turn around and, and I'll just like, you know, tell them that hey, you know I just heard you say whatever and they're like haaa! Oh my god! You know, like yabai tte kanji de.

like "yikes!" 
Though not a complete sentence as in Nishimura's study, there is a portmanteau phrase at the end of the excerpt, compounded from the English phrase "like "yikes" and the Japanese phrase "yabai" tte kanji de, or "as if to say "yikes", When the two are put together, they merge into the form "like 'yabai' tte kanji de." In this phrase, tte kanji de can be translated as "being like." Thus, the phrase consists of a construction of the Japanese word yabai being book-ended by the element of "as if" with the English "like" at the beginning and the Japanese tte kanji at the end. This type of redundancy often characterizes portmanteau speech. It produces a sentence or phrase that is made of two phrases in each language that are correct if looked at as separate components and tend to hold the same content, such as "like" and tte kanji. However, taken as a whole, a portmanteau sentence usually violates the rules of both languages to make a complete sentence. These varieties of code-switching listed above, and portmanteau sentences in particular, are unique to Nishimura's "mixed variety," and therefore this entire conversation is not merely English with some Japanese mixed in. Although the actual speech of the participants is made of mostly English morphemes, the grammatical structures used by the postwar speakers share elements of both languages.

\subsection{Dubious structures of code-switching}

Aside from varieties of code-switching that are clearly attested to in previous literature, there were occasionally idiosyncratic and hard-to-define features that are worthy of mention. The simplest form of this consists of a doubtful case, since it consists of a sentence which involves only two words, a subject in English and a predicate, specifically a verb, in Japanese. Following Nishimura (1995b), since there are exactly 
equal amounts of words, it can be tempting to think it truly is mixed speech; however, since the Japanese word has more morphemes, it may just as easily be a Japanese-English code-switch according to Myers-Scotton. For the sake of this study, it will be treated as "mixed" speech, since either word in the sentence can be treated as a borrowing from either language.

(9) "Mixed" speech: you sageru [Group 1]

1. Noriko: I always * had *, nandake *, her clothes that she couldn't wear *, osage, what is it, $\quad$ is it called osage osage te iundake? Like things that, the clothing that, osage te iun dakke? What was it, is it called osage

you know the clothing that she wore that she couldn't wear anymore so she would give it.

2. Mary: Hand-me-downs, hand-me-downs, but I don't know what the Japanese

3. Noriko: Hand-me-downs! Hand-me-down te Nihongo de nan dakke? what's [it] called in Japanese 4. Mary: I always just said o furu o morau dakedo, furui... although it is to receive ofuru, [is it] old?

5. Noriko: Ofuru, ofuru, osa-, osage da to omou, it's like, you sageru, it's like *, you 
[experimenting with words] I think it's osage, hand it down

6. Mary: Lower

7. Noriko: You take it down, like lower, osageru, osage, osage tte iun dakke? I can't

[to] osageru, osage, is it called osage?

remember!

In line 1, Noriko says “osage te iun dakke” asking for the Japanese equivalent of "hand-me-down", which she at first guesses is osage. More importantly, this prompts the use of a quotation of the English word "hand-me-down" in a Japanese context, where she asks for its definition. In contrast, Mary in line 4 gives another possible Japanese translation, "o furu o morau dakedo," but this time as a Japanese quotation in an English environment. Finally, while continuing to search for the proper translation, Noriko gives a rationale for why she rendered it as she did. In line 5, Noriko does this by combining the verb from which the Japanese word for "hand-me-down" is derived, sageru, with an English subject, in this case "you".

This code-switch is rather multifaceted. The source of the speaker's confusion is that while the word "hand-me-down" in English has a transitive meaning, in which the verb "hand" or "hand down" takes the direct object "me," the correct Japanese version is actually a nominal form derived from the intransitive counterpart to sageru, which is sagaru. The result is osagari, which translates to "something coming down." The assumption that both languages use a transitive verb to form the word in question is perhaps a cause of confusion for the Japanese version, and is the sign of the grammar of 
one language intruding into another. This intrusion can also be detected in another doubtful example like the one below:

(10) Mixed speech: they henna kidotteiru taido [Group 1]

1. Mary: What really irritates me is that nanika, nihongo no josei ga sa, eigo de, nanika

what is it, you see Japanese-speaking women

setsumei suru deshou? This is (?) cooking Chotto sumuuzu ni namaiki ni kikoenai?

try to explain stuff in English right? Doesn't it come across as smooth and conceited?

2. Noriko: Namaiki ni kikoeru

It comes across as conceited

3. Mary: First of all, Nihonjin nano ni, eego de kurasu oshieteimasu, because they hen na, although they're Japanese, they're teaching in English [have a] weird kidotteiru taido, I dunno.

sense of confidence

In line 3, Mary puts together an English subject with a Japanese nominal as a predicate. However, there is no copula or verbal to make this a complete sentence in English or in Japanese, which at times permits the copula to be dropped. This lack of a copula or verb is a common phenomenon in Japanese and, in some contexts, grammatically correct for Japanese. Therefore, though not a portmanteau construction, it still suggests that Mary's sentence might be "mixed" speech. 
Lastly, though not strictly a code-switch by the definition of this study, there were definite examples of intrusion from the grammars of other languages in speech that is consistently made of the words of just one language. The next excerpt (14) shows the example of omission of the English indefinite article.

(14) Omission of indefinite article [group 1]

1. Noriko: Oh NHK world news is * usually, usually English with the subtitl-, like * docchi ka na? It's combination. Sometimes a program is in English and then there's, which is it there will be a Japanese subtitle, or its in Japanese and it has a English subtitle. Or where they're speaking like cooking channel, it's kind of like, both.

The native Japanese speaker, Noriko, who normally uses indefinite articles in English, drops them when she says "it's combination." This suggests that the noun here is being treated more like a borrowed Japanese nominal, which does not need an article. Though sentences such as these involve the grammar of each language, for the purpose of this study they will not be considered code-switching.

\subsection{Summary}

In conclusion, when put in a similar context as the Japanese-Canadians in Nishimura's study, the heritage speakers in this study at times use language that is primarily English and at others use language that is primarily Japanese. Furthermore, each group code-switched parts of speech that largely agreed with the earlier results as 
presented by Nishimura. The second and third groups, which spoke primarily either Japanese or English, kept mostly to single words, especially nouns. On other hand, Group 1, which intermixed the two languages more freely, used a greater variety of discourse and grammatical parts of speech, oftentimes in the same place and at the same time. However, unlike Nishimura's study (1995b), the group that used "mixed" speech also used slightly fewer parts of speech when borrowing, suggesting a greater consistency than earlier studies. Last of all, the second-generation speakers in this study acted differently than in previous studies and spoke almost entirely in English with occasional Japanese borrowings, instead of in a more even mix of the two. At this point, there is no clear relationship between the dominant language and the social context of the participants. This study will present a possible answer for this variation with the help of later discussions of the language attitudes of the participants in the following chapter. 


\section{Chapter 5}

\section{Discussion and Conclusion}

In this chapter, I answer the research questions originally posed in the beginning of the study. I start by addressing the questions with the information from the group conversations, and then I give an account of the different attitudes the postwar speakers have towards the languages they speak as expressed through their personal interviews. Next, I compare the heritage speakers involved in this study with the second-generation speakers in Nishimura's study in order to determine what linguistic trends may be at work in their speech, and show how this relates to Nishimura's earlier studies of Japanese-English code-switching. Lastly, I use the information gathered in order to answer the research questions and provide some possible connections between the education of the speakers and their choice of language.

\subsection{Research Questions Addressed by Group Conversation Analysis}

To start off, I summarize my findings for Research Question 1: "What is the dominant language within the discourse used by postwar speakers, if there is one? If it varies, what are the conditions that make it vary?" When asked to converse in the presence of a native speaker, as in Nishimura's study, the heritage speakers in this study sometimes use language that is primarily English, and at other times use language that is primarily Japanese. Furthermore, the use of Japanese in primarily English speech varies drastically by group. However, given the data provided so far, it is difficult to answer 
why it varies, so a discussion of this topic will take up the final part of this chapter, once all the data has been discussed.

As for Research Question 2: "What grammatical items do postwar speakers use when they code-switch? If they use different features from the group studied by Nishimura, how do the speakers differ?" I conclude that each group's code-switched parts of speech largely agree with the earlier results as presented by Nishimura. Most of the code-switching cases found in Group 2, which spoke primarily Japanese, and Group 3, which spoke mostly English, were single words, especially nouns. Group 1, which intermixed the two languages more freely. It showed code-switching using a greater variety of discourse parts of speech, including such elements as clitics and repetition, as well as overlaps of grammatical parts of speech such as quotation frames and verbs. However, compared to Nishimura's study, this group used slightly fewer parts of speech when borrowing single words, suggesting a greater consistency in sticking to one language at a time than earlier studies.

Lastly, Research Question 3 is as follows: "In particular, what variety of codeswitching is used by the second generation of postwar speakers when speaking to native speakers and fellow second-generation heritage speakers? Is their speech closer to the "mixed variety" or borrowing as defined by Nishimura? If they act similarly to Nishimura's group, how do they compare to older or younger generations?" The secondgeneration speakers in this study acted differently than in previous studies, and spoke almost entirely in English with occasional Japanese borrowings instead of a balanced combination of the two. These results may have differed from earlier studies for multiple 
reasons, such as changing historical conditions or lack of familiarity between the speakers, and so will be more clearly addressed in the following sections when the dominant language choice is examined in greater detail.

\subsection{Language Attitudes of Postwar Speakers}

The personal interviews following the group conversations shed some light on the nature of the heritage speakers' choices of language as described in this study. This discussion below both answers the last research question of the study, "What attitude do postwar speakers self-report towards the two languages that they speak?" and also clarifies the issues surrounding the choice of dominant language in the participants.

To start, some general trends seem to mark this particular set of participants, and may be taken as characteristic of all three groups. On the whole, many of the postwar speakers self-reported a preference for Japanese over English on the basis that it was more cultured, though when pressed, often had greatly varying ideas of what that meant. Some speakers reported a respect for Japanese based on its relative inaccessibility and their own lack of ability to be perfectly fluent in it (Katherine, Diane), its long history (Mary, Samuel, Shizuko), or its different social registers and levels of politeness (Mary, Hannah, Lisa). The two native speakers, Yumiko and Shizuko, who were not educated in the U.S., also reported that they felt that Japanese had a richer vocabulary. One of the second-generation participants, Lisa, even felt that the English language did not have a unique culture behind it. Curiously, the only speakers who felt that English was in some sense culturally superior were two of the participants who filled the native speaker role, 
Shizuko from Group 3 and Noriko from Group 1, who was partly educated in the U.S. Noriko appealed to the international use of English, while Shizuko felt that English allowed for greater precision in expressing meanings.

Somewhat ironically, the more a participant is educated in the U.S., the more they seem to prefer Japanese. Since both of the native speakers, who at times preferred English, were in their 50's and over, it is possible that the preference towards English reflects an older attitude towards the languages, since the other speakers, who favored Japanese, were in their 50's or younger. However, this may also suggest a greater similarity of the heritage speakers who were mostly educated in America towards the two second-generation speakers, as opposed to those who were primarily educated in Japan. Also, among the heritage speakers in the study, there is no significant difference in language attitude between Hafu speakers and those who do identify as such. Therefore, the distinction between generations, in the strict sense of place of birth or race, is undermined by these differences.

Similarly, the speakers' positive experiences and ability to retain their language had many common themes. For instance, many of the participants noted that their Japanese abilities helped them to find jobs for Japanese-run companies in the U.S. and earn a livelihood, which in turn helped them to retain their speaking ability (Noriko, Hannah, Samuel, Lisa). This stands in stark contrast to Nishimura's observation that the Kika-Nisei, who had high Japanese fluency since they were educated in Japan, had a hard time finding jobs in North America (1995a, 161). Furthermore, social media played a great role in many speakers' language retention, such as the Hafu Facebook group 
mentioned in Methodology, in which many of the participants in the study were members. Instead of relying on the close physical proximity of an ethnic neighborhood to promote fluency and fellowship, many of the participants speak to each other and maintain relationships across state lines. Even by themselves, these observations seem to suggest a hospitable climate for Japanese speakers in North America.

While the postwar speakers expressed positive views about the Japanese language in general, it does not mean their experiences were entirely positive. For instance, some of the older heritage speakers who were educated in the English language, particularly some of the older Hafu speakers, reported deeply negative experiences and discrimination from both Japanese and English speakers growing up, particularly Mary and Samuel, who were both in their 50's. Many of the other participants, such as Noriko, Diane, and Hannah, who were partly educated in America, also reported occasional cultural misunderstandings by English speakers. Similarly, the two second-generation women in their 20's also claimed to feel out of place, particularly in school environments in the U.S., and reported that they both abandoned the use of Japanese as children as a result of these experiences. Therefore, Japanese-English heritage speakers in the U.S. did not cease to struggle with their linguistic identity even after the internment camps were disbanded, but continued to feel insecure about their identity well into the present.

To sum up, most of the respondents who were educated both in America and Japan self-reported a very high opinion of Japanese as opposed to English, while those who were educated in Japan occasionally felt English to be superior in certain respects. Nevertheless, not all of the postwar speakers who preferred Japanese actually used the 
language when speaking to fellow postwar speakers, even in very similar situations.

Therefore, if language attitudes have any part to play in the choice of dominant language, they may relate more closely to the upbringing of each participant than to their actual stated opinions.

\subsection{Three Forms of Speech in Postwar Speakers}

At this point, all research questions are answered except for the final part of question 1, "If [the dominant language of the conversation] varies, what are the conditions that make it vary?" This question is particularly elusive because it deviates from the prior observations by Nishimura, in which the same group of participants produced three different "varieties" of code-switching, a "basically Japanese variety," and a "basically English variety," and a "mixed variety," depending on social contexts in which the addressee played a primary role (1995b). In the current study, however, three different groups of participants each produced one of three aforementioned "varieties," but all in similar social contexts. Therefore, the individual participants need to be examined more closely in order to find a difference.

To start, in contrast to Nishimura's initial study, the speakers analyzed above came from a variety of different backgrounds and levels of exposure to Japanese and English. While all of Nishimura's subjects were second-generation Japanese-Canadians who were educated in North America, the heritage speakers considered here had different degrees of education in the U.S. and were largely born in Japan, with only a handful of exceptions. However, an attempt was made to approximate Nishimura's conditions by 
pairing speakers who were mostly educated in Japanese with those who were primarily educated in English, where those who had completed Japanese middle school (the equivalent of the ninth grade in the American educational system) would be considered native speakers. Under these circumstances, the researcher initially expected that Japanese would have been the dominant language in most of the cases studied.

However, contrary to the initial assumptions of the researcher, this study shows that Nishimura's division of Japanese-English code-switching into three "varieties" is still applicable to the heritage speakers who are active today. Furthermore, the researcher also initially posited that the overlap of grammars involved in the second generation Japanese-Canadians studied by Nishimura would not occur in heritage speakers who had arrived in the U.S. after the 1940's, but there was grammar overlap for the speakers in the first group of this study, who were all women who all immigrated to the U.S. after the 40's. Therefore, the initial supposition of the researcher that the breakup of the JapaneseAmerican neighborhoods caused or hastened the development of "mixed" speech is false, and the cause of "mixed" speech must be found elsewhere.

It should be noted that this study found that the three code-switching "varieties" are used by speakers who are not second-generation. For instance, the first and second groups were composed of heritage speakers who had spent at least some of their earliest education in the Japanese school system. Furthermore, the native speakers, particularly Noriko in Group 1, were not immune to the effects of English either, and in one case even used a grammatical overlap in her conversation, something that Nishimura attributed to Nisei or second-generation Japanese-Canadians. Because of the continuum 
of different degrees of education in the two countries at work in postwar speakers, it is shown that Nishimura's "varieties" can appear even in those who have spent most of their childhood in Japan, and it is likely that their presence may even vary depending on how long each speaker has spent in each country.

The above findings contrast with the community studied by Nishimura, who stated that the Issei, or the first generation of Japanese-Canadians, had very limited use of English. (1995b, 126). Of all the participants in the study, only the native speaker for Group 2, Yumiko, preferred the use of Japanese during her personal interview, while the rest of the participants, many of whom were born in Japan and could be considered firstgeneration, completed their interviews in English. Therefore, although the majority of the participants were largely born in Japan, they cannot be characterized as first-generation speakers according to Nishimura's definitions.

In this sense, though a direct comparison in all points is not possible, the postwar speakers who were educated in both countries present an interesting contrast to the prewar Japanese-Canadian second-generation speakers known as Kika-Nisei, who were born in Canada but were educated in Japan. Nishimura did not address the state of the KikaNisei in her papers, aside from noting that Nisei treated them similarly to native speakers, using an overlap of grammars in their conversations with them, although she did not note whether the Kika-Nisei also answered them in the same way. However, she explains that "their command of Japanese is practically that of native Japanese, with limited English," suggesting a lack of English fluency which none of the heritage speakers who were educated in both countries in this study seemed to have (1995a, 158). Although the Kika- 
Nisei were not the subject of Nishimura's research, it should be noted that the postwar speakers who were educated in both countries do not act according to the norms that Nishimura established for either Kika-Nisei or for Nisei speakers.

Lastly, the second-generation individuals in Group 3 stood in contrast to the second-generation speakers featured in Nishimura's study. As shown by the mixed speech that they used with a native speaker, the Nisei in Nishimura's study had a stronger proclivity towards Japanese because they used it more interchangeably with English during their conversations. On the other hand, the two second-generation women in this study, Lisa and Katherine, spoke English to each other with occasional borrowing from Japanese. As a result, this would seem to show that, contrary to an increasing acceptance of Japanese by postwar speakers, the current second generation is actually embracing English more quickly.

However, when each participant is taken individually, the picture becomes somewhat different. As noted above, one of these two participants, Lisa, had spent some of her early childhood and a year of middle school in Japan, while the other, Katherine, did not spend any time in Japan at all, aside from occasional vacations. Initially, the conversation swung towards the exclusive use of Japanese between the native speaker Shizuko and Lisa, while Katherine, who was not comfortable speaking Japanese to them, directly asked for the conversation to be in English. Much of this can be directly attributed to the lack of familiarity between these participants, but it remains significant that one of the second-generation heritage speakers was perfectly fine speaking Japanese to someone they were not familiar with while the other was not. Therefore, the 
determination of the dominant language likely relied on the specific background of the participants.

\subsection{The Relationship between Dominant Language and Education}

The two second-generation participants, Lisa and Katherine, differed very openly about their use of Japanese during the opening of their group conversation, in the dialogue for Group 3. However, since they were also the two speakers who openly claimed in their interviews that they stopped speaking Japanese as children, it is necessary to explain their divergence in behavior.

Lisa and Katherine's experiences at home shed some light on the difference between their respective language choices. All of the respondents who were educated in both the U.S. and Japan reported that they spoke Japanese or at least heard spoken Japanese with their family. This includes Katherine, the second-generation participant who was only educated in the U.S. It has already been noted that the other secondgeneration participant, Lisa, had spent at least a year being educated in Japan. Katherine, on the other hand, did not attend school in Japan and, moreover, was actively tutored by her exclusively Japanese-speaking parents to learn English, since they were concerned that she would not learn it adequately from them. Therefore, although she continued to hear Japanese constantly while living at home, it was not enough to counteract both her embarrassment over her Japanese identity at school as well as her parents' own concern for her ability to integrate with American society. 
Lisa, who faced similar embarrassment at school, also abandoned her heritage language, and also only heard Japanese from her mother, while her father used English. Given that their home experiences were similar, it seems more likely that Lisa's education in Japan was the reason that she not only could comprehend Japanese, but could also use it to converse with strangers as well. Therefore, it seems that education in larger society is more important to the preservation of bilingualism than exposure to a second language in the home. This, however, does not deny that a supportive environment or immersion at home affected the participants, or is necessary for the development of a heritage language. Every one of the heritage speakers spoke Japanese with their family in some capacity. However, in determining which is the more important factor for speaking the heritage language with outsiders, it seems that education outside the family is more crucial.

The degrees of education in Japan also explain the difference between the dominant language choice between Group 1 and Group 2. In both cases, two heritage speakers who had been in the Japanese school system for no more than three years spoke to someone who had at least finished middle school in Japan; as well, at least two of the participants knew each other well, though all were in the same social media group. However, in Group 1, the participants code-switched frequently, and at times even used overlapping grammar. In Group 2, the participants maintained Japanese constantly throughout the conversation, and even treated the code-switches they did use as Japanese borrowings. 
There are a handful of differences that may explain the discrepancy between the two groups. In the second group, one of the heritage speakers who had been educated in both countries, Samuel, had spent most of his childhood up through his early teens in Japan, but transferred to an English-speaking military-run elementary school to finish his education before moving to the U.S. Though he lived on a U.S. military base, this may have also had an effect on his Japanese proficiency. However, the most significant difference between Group 1 and Group 2 involves the participants filling the role of native speaker in each discussion. In Group 1, it was a speaker who had only finished middle school in Japan, whereas in Group 2, it was someone who had spent the entirety of their childhood in Japan.

The role of the preferences of the native speaker in each group seems to be significant in determining the language choice in the current study's dialogues. In Group 2, Samuel, who started speaking English in the beginning of the dialogue directly asked the other two participants to determine the language of the conversation. Yumiko was the native speaker and spoke primarily in Japanese, whereas the other native speaker Hannah indicated that she could speak either language, Yumiko directly asked for Japanese, which in turn became the dominant language. On the other hand, in Group 1, the native speaker, Noriko, did not place any such request or requirement on the rest of the group, so the speakers used the two languages more freely. It seemed that the native speakers had influence over which language would be preferable, at least in these two groups.

\subsection{Possibilities for Future Developments}


In the case of this study as opposed to Nishimura's, there are some other differences besides the education of the participants. In particular, there is the native speakers' influence over the language choice, which Nishimura did only passively, since she played the native speaker role in her study and kept herself from unduly influencing the others (1995a). In this sense, the native speakers in the current study had a bit more freedom to participate in the conversations and, hence, influence language choices. However, there still remain multiple issues that make it difficult to conclusively determine the state of Japanese-English bilingualism in the contemporary U.S.

Naturally, the greatest hindrance to this study is its extremely small sample group. With only nine participants, it seeks to outline the vast and complicated state of postwar Japanese-English bilingualism in the U.S., which varies wildly depending on factors including, but not limited to, age, gender, historical context, and even race, in the case of those who are part Japanese. Oftentimes, multiple characteristics were part of the same individual, and thus the real cause of a code-switch or choice of dominant language was often ambiguous. For instance, there were only two second-generation individuals in this study, each who had multiple important distinguishing characteristics, such as having English speaking parents and some degree of Japanese education. For example, in the case of Lisa, the study was not able to distinguish between the fact that she was halfJapanese and the fact that she studied in Japan as influencing characteristics on her language choice. Similarly, since most of the participants were female, with the exception of Samuel, it is difficult to tell for certain whether the speech described above is unique to them or whether it applies to all Japanese-English heritage speakers. A much wider 
sample group, which is able to select participants based on common characteristics with only one variation, will be necessary in order to more thoroughly explore whether the use of Japanese among postwar heritage speakers is really different from the data featured in Nishimura’s study (1995b).

Similarly, as the study suggested above, there appears to be a relationship between the amount of time spent being educated in Japanese and the degree to which a given speaker will code-switch. Unlike Nishimura's study, which attributed language choice solely to the generation the speaker belonged to, this study admits the possibility that code-switching may happen on a sliding scale based on education. To pursue the necessary amount of code-switching needed to make these distinctions would also require a larger number of participants. While this is not a question that can be answered solely on the basis of the given data, it does present an avenue of research for future studies.

This study also charts processes that may be in enormous amounts of flux, such as the rise or decline of favorable opinions towards Japanese in America. The heritage speakers who are being raised in the U.S. with this more recent shift in attitudes to a positive regard for Japanese culture would be interesting to compare to the participants in the study. The heritage speakers in their early twenties from this study reported negative attitudes in school and that the acceptance of Japanese pop culture in the U.S. was still, for them, a recent phenomenon. Therefore, the rise of a third generation which has not yet attained adulthood, or Sansei, ought to be compared to those who are more recent arrivals. 
Finally, the study of code-switching grammar is still under debate. As the argument between Poplack and Myers-Scotton shows, there is still no consensus as to how code-switching is processed in the human mind. Although this study in many ways confirms Nishimura's study of Japanese-English code-switching, which generally sides with Myers-Scotton, the borrowing used by Group 2 at times suggests a view of codeswitching closer to that of Poplack. Much work still needs to be done in order to resolve the conflict between the two theories, which may incorporate at least some synthesis like Nishimura's attempt to unite both theories. In the interim, this study wishes to confirm the relevance of Nishimura's research (1995b) on "varieties" in code-switching in Japanese-Canadian Nisei in North America, while extending her categories to include speakers who do not fit her initial criteria. This research also suggests that given the current state of Japanese-English heritage speakers in the United States, the choice of language in a group conversation with other heritage speakers depends on education abroad, supplemented with support from the home.

\subsection{Conclusion}

Judging from the participants in the study, the current Japanese-English heritage speakers in America maintain a remarkable degree of fluency in either language, but it is a fluency dependent on education outside of the U.S. In this sense, the breakup of the Japanese neighborhoods in America and in Canada did contribute greatly to the weakening of bilingualism in North America, since it removed a set of conventions and social structures that made Japanese-English bilingualism possible without the need to attend foreign schools (Nishimura 1995b). The current heritage speakers in the United 
States thus speak a language that is held together by family ties, social media, and the recent rise of Japanese popular culture. This recent popularization was confirmed by the two young second-generation participants, who both expressed interest in Japanese culture and how that helped them appreciate their heritage. It remains to be seen whether the generations that follow will also feel the same way. 


\section{References}

Bentahila, Abdelali and Eirlys E. Davies. 1998. "Codeswitching: An unequal partnership?" In Codeswitching Worldwide, edited by Rodolfo Jacobson, 25-49. Trends in Linguistics: Studies and Monographs 106, edited by Werner Winter. Berlin: Mouton de Gruyter.

Blom, Jan-Petter, and J.J. Gumperz. 1972. "Social meaning in linguistic structures: Code switching in northern Norway." In Directions in Sociolinguistics: The

Ethnography of Communication, edited by John J. Gumperz and D. Hymes, 407434. New York: Basil Blackwell.

Boeschoten, Hendrik. 1998. "Codeswitching, codemixing, and code alternation: What a difference." In Codeswitching Worldwide, edited by Rodolfo Jacobson, 15-24. Trends in Linguistics: Studies and Monographs 106, edited by Werner Winter. Berlin: Mouton de Gruyter.

Gumperz, John J. 1982. Discourse Strategies. Cambridge: Cambridge University Press.

Jorden, Eleanor Harz, and Mari Noda. 1987. Japanese: The Spoken Language. Part 1. New Haven, CT: Yale University Press

Labov, William. 1972. "On the Mechanism of Linguistic Change.” In Directions in Sociolinguistics: The Ethnography of Communication, edited by John J. Gumperz and D. Hymes, 512-538. New York: Basil Blackwell.

Maynard, Senko K. 2008. "Playing with multiple voices." In Style Shifting in Japanese, edited by Kimberly Jones and Tsuyoshi Ono, 91-129. Philadelphia: John Benjamins Publishing Company.

Minegishi Cook, Haruko. 2008. "Style shifts in Japanese academic consultations." In Style Shifting in Japanese, edited by Kimberly Jones and Tsuyoshi Ono, 9-38. Philadelphia: John Benjamins Publishing Company.

Myers-Scotton, Carol. 1993. Duelling Languages: Grammatical Structure in Codeswitching. New York: Oxford University Press.

Myers-Scotton, Carol. 2006. "Grammars in Bilingual Contacts." In Multiple Voices: An Introduction to Bilingualism, 233-287. Malden, MA: Blackwell Publishing.

Nishimura, Miwa. 1995a. "A Functional Analysis of Japanese/English Codeswitching." Journal of Pragmatics 23 (2): 157-81, https://doiorg.proxy.lib.pdx.edu/10.1016/0378-2166(93)E0103-7.

Nishimura, Miwa. 1995b. "Varietal Conditioning in Japanese/English CodeSwitching." Language Sciences 17 (2): 123-46, https://doiorg.proxy.lib.pdx.edu/10.1016/0388-0001(95)00005-G. 
O'Grady, William, and Videa de Guzman. 2017. "Morphology: The Analysis of Word Structure." In Contemporary Linguistics, edited by William O'Grady and John Archibald, 121-165. Boston: Bedford/St. Martin's.

Okamoto, Shigeko. 2008. "Speech style and the use of regional (Yamaguchi) and Standard Japanese in conversations." In Style Shifting in Japanese, edited by Kimberly Jones and Tsuyoshi Ono, 229-249. Philadelphia: John Benjamins Publishing Company.

Poplack, Shana, Susan Wheeler, and Anneli Westwood. 1989. "Distinguishing Language Contact Phenomena: Evidence from Finnish $\square$ English Bilingualism.” World Englishes 8 (3): 389 -406, https://doi-org.proxy.lib.pdx.edu/10.1111/j.1467971X.1989.tb00677.x.

Sankoff, David, and Shana Poplack. 1981. A Formal Grammar for Code-Switching. Edmonton: Linguistic Research. Distributed by ERIC Clearinghouse, https://files.eric.ed.gov/fulltext/ED232442.pdf.

Tannen, Deborah. 2005. Conversational Style. Oxford: Oxford University Press. Adobe Digital Editions.

Tsujimura, Natsuko. 2007. An Introduction to Japanese Linguistics. $2^{\text {nd }}$ ed. Malden, MA: Blackwell Publishing.

Woolard, Kathryn. 1989. Double Talk: Bilingualism and the Politics of Ethnicity in Catalonia. Stanford, CA: Stanford University Press. 
Appendix A:

Transcription Conventions

italics code-switch

[brackets] commentary

/ division between morphemes

* audible hesitation

(?) inaudible speech

bold use of Hafu speech

underline added emphasis by researcher 
Appendix B:

Conversation and Interview Transcript

(Numbers in parentheses are timestamps for each excerpt in the conversation)

\section{Group 1}

$\mathrm{N}$ : Who want/s to start? D?

D: *Well, first of all, *hajime/mashi/te, N-/san,

N Hajime/mashi/te

D: I think I'/ve seen your name in the Hafu facebook,

$\mathrm{N}:$ *Yeah I think we'/re friend/s

D: And *, but I'/ve never had the pleasure of actual/ly talk/ing to you, voice to voice so

$\mathrm{N}$ : Absolute-, Yeah

M: (?)

D: I'/d like to apolog/ize first of all because I just complete/ly lost track of time; I'/m retire/d now, so I do/n't watch the clock, which is good news, but then I embarrass $\mathrm{my} / \mathrm{self}$ like this today, so

N: That/'s okay!

D: I/'m grateful you are still available

$\mathrm{N}$ : No problem at all

D: Okay!

M: Just thank you, Honto ni.

D: And then M and I talk to each other just about every week so

N: Okay.

D: Yeah, yeah 
$\mathrm{N}$ : M and I spoke maybe what, two week/s ago, maybe?

M: That depend/s

N: Yeah

M: Remember *, somebody come/s up, and I du/n/no like you know to be Half Japanese, there are so few of us, so when you find one, she's like I mean, you don't know each other, but I feel like we're related in a bizarre way, cause you understand each others' when you have a Japanese American upbringing like this you know, plus there are so few of us that actually speak it too, especially in our age group, so you just feel...sugu shitashimi o kanjiru * I gonna be (?), I sometimes don't even give you a to(?), I wanna be friends with her

N: So D, D did you grow up in Japan?

D: Um, I moved to Southern California when I was eight, hassai no toki.

$\mathrm{N}$ : Hassai no toki? Okay. I was uh sixteen. Almost sixteen. Jyuu-gosai to jyuu ikkagetsu kana? Yeah.

M: Did you guys ever get told, or your mom was told, oh don't bother with Japanese, cause you don't want to confuse the child, so you know let the Japanese go and stick to American (?), did you guys, did your parents (?)

N: No!

D: Nihongo wa ganbare, Nihongo ganbatte ne, te iutteru kedo, otoosan wa ne, mo America ni kita kara, chanto Eego naranai to, nihongo hanashitara dame, te iuwareta

$\mathrm{N}:$ Really!?

D: Okaasan to watashi wa...Nihon

D: Otoosan no koto wa zenzen ohanashi shinai kedo, we weren't backtalking him, my dad, he couldn't understand Japanese, but we would talk, and he'd sometimes hear us, and he'd think we were talking about him. 
$\mathrm{N}$ : In a way, I was lucky to, * three of my younger sisters don't have that capacity, you know, they can actually have a very miminal conversation, but you know, keigo, they can't do, they can't speak keigo, or business, you know business language. So in a way, I guess, I was lucky, maybe, so?

M: Well the thing is, were all, all three of us are the oldest, cause Debbie is also the oldest of three, I have a younger sister, J, I don't even how to speak of him you know tabun mattaku dekinai koto mo aru.

$\mathrm{N}$ : Yeah

M: We're the oldest, were the responsible ones, of course, happa no dakara, we're the most favorite ones so of course we have to speak Japanese.

$\mathrm{N}$ : Yeah

M: That was an easy class!

$\mathrm{N}$ : What?

M That was an easy class! Nihongo dekiru kara.

$\mathrm{N}$ : It was! It was a easy, easy A, but we and at the same time, we had like six Hafus in that class, in Sacramento, in Sacramento, yeah at Sac State, so all of us, didn't have to * go to school go to class...

M: They say you can survive in Tokyo with only 800 kanji, so I'm like, oh wow is that all!? You know, whatever. Kantan ni iu ne, minna, so.

N: Cause you said you were what eight, when you moved?

D: I was eight when we moved to Southern California.

N: Southern California

D: Ni nensei datta?

N: Ni nensei? Yeah. 
D: Obachan ga tottemo kawaigatteta kara,

N: Sou da yo ne

D: Kaachan te iu wake, kaachan

$\mathrm{N}$ : Yeah

D: Obachan? *My mother was "Mama", and then obachan wa "kaachan" so when she $\mathrm{N}:$ Oh really!

D: She would drive me around downtown, and I would say "kaachan, kaachan!" so...

D: Dakara, kaachan ga itsu mo ne, ocha nodeiru, asa no ocha o nondeiru toki, kono tegami tottekara, nankai mo yomu wake, ikkagetsu demo, mai asa yonde, atashi no koto kangaeteru kara, we have that *kokoro to kokoro connection

N: Yeah

D: So I am emotionally motivated to keep up with my Japanese cause I don't want to lose that wonderful relationship with my relatives.

$\mathrm{N}$ : Her name is $\mathrm{M}$, and I mean, we call, I mean I call her $M$-ba, M-bachan M-obachan and but M-obachan you know

$\mathrm{N}$ : I always * had *, nandake *, her clothes, that she couldn't wear, um, osage, osage te iundake? Like things that, the clothing that, osage te iun dakke? What was it, you know the clothing that she wore that she couldn't wear anymore so she would give it

M: Hand-me-downs, hand-me-downs, but I don't know what the Japanese

$\mathrm{N}$ : Hand-me-downs! Hand-me-down te Nihongo de nan dakke?

M: I always just said o furu o morau dakedo, furui...

N: Ofuru, ofuru, osa-, osage da to omou, it's like, you sageru, it's like *, you 
M: Lower

$\mathrm{N}$ : you take it down, like lower, osageru, osage, osage tte iun dakke? I can't remember! Anyway! She, I used to wear her clothes...

M: You're like "Arigatou”

M: What really irritates me is that nanika, nihongo no josei ga sa, eigo de, nanika setsumei suru deshou? This is (?) cooking. Chotto sumuuzu ni namaiki ni kikoenai?

N: Namaiki ni kikoeru

M: First of all, Nihonjin nano ni, eego de kurasu oshieteimasu, because they hen na, kidotteiru taido, I dunno.

M: I haven't been there since '91. Maybe 30 years now

$\mathrm{N}: ' 91$ is 30 years!

M: I know! San-jyuu nen ni itan desu ga, naze? Because when I speak Japanese here, (?) I do, it's not like Nihongo wa jyoozu desu ne, it's more like, naze?

$\mathrm{N}:$ Naze?

$\mathrm{M}:$ Naze?

N: Yeah, Every time I, every time I go back to Japan, you know I listen to *, you know, jiro jiro mirarerun da yo ne?

M: Yeah, yeah

$\mathrm{N}$ : Cause you know, I'm I'm tall, I'm 5 8, so I get on the train, and people start like looking at me like up and down, deshou? And then they'll start like whispering, you know in Japanese, and then I'll turn around and, and I'll just like, you know, tell them that hey, you know I just heard you say whatever and they're like haaaa! Oh my god! You know, like yabai tte kanji de. 
M: ? That happened a lot to me, with my relatives *, you know M-chan wa haafu blah blah blah, and they'll say yappari gaikokujin dakara, kurutteru(?) yo ne, mitai ni, you know that kind of Japanese, and then and then you know since they're my elders that's the (?) so I say nothing, and then later on, M-chan, you know, I'm like hai and they're like are, $M$ nihongo dekitara (?) yuwanaide yo, now they're mad at me cause I could tell that they understood that they were badmouthing me, has that happened to you?

$\mathrm{N}$ : Yeah

M: Like (?) nande iwanaide yo. Betsu ni,

N: Yeah

M: Betsu ni dare to atte mitai na, Then they'd be feel guilty and (?) slam down okozukai ageru kara acchi ikinasai mitai na.

N: But I'm sure you've probably seen a lot of like cooking cooking channel, deshou?

M: When you listen to the NHK, Japanese or English, they have both

$\mathrm{N}: \mathrm{Ok}$

M: So

$\mathrm{N}$ : Oh NHK world news is * usually, usually English with the subtitl-, like * docchi ka $n a$ ? It's combination. Sometimes a program is in English and then there's, there will be a Japanese subtitle, or its in Japanese and it has a English subtitle. Or where they're speaking like cooking channel, its kind of like, both.

M: Yeah. The thing is, what people like speaking and baking in these in Japanese, minna sa, atashitachi ga Nihongo to eego shaberu toki, konpurekkusu? Because, they would study Japanese for years, and they still sound so bad. It's the l's and the r's. Hatsuon ga ammari jyoozu jya nai kara. You know, do you realize you have spent millions of dollars (?)

$\mathrm{N}$ : Oh are you talking about the Japanese?

M: Yeah. Nihonjin no hitotachi

$\mathrm{N}$ : Well there's no errrrr and luhhhhh sound in * in Japanese, * yeah in Japanese dakara $s a$. It's it's hard to, yeah 
N: Mukashi wa chugaku karadatta desho, yeah

M: Yoochien kara issho ni, nihongo mutsukashii kara, (?) kedo, nihonjin no hitotachi ammari eego jyoozu ni naranai no

$\mathrm{N}$ : Yeah, the only problem, only problem is that * English education in Japan is that, yomikaki wa dekiru no ne? Dakedo, the conversation is just its so difficult unless they go, you know, unless they go abroad and you know study in in Canada, or US, or the UK, * for some reason I guess, they can't hear the language very well, I mean its its all listening, its all listening skills, and they really don't have the listening skills.

M: And also, I have a Japanese girlfriend who (?) on studying here in the US and went back to Japan for high school, so her English was flawless, (?) you know you think that'd be a good thing, but gyaku ni ijimerateta. Yappa, omae wa nanda to, eego mo shaberareru (?) you know.

$\mathrm{N}$ : Is that, is that is that a long time ago

M: Maa ne.

M: (?) I hope it's different now, but yappari, eego, nihonjin no hito ga eego oshieteru yori, eego ga jyoozu ni shaberarenai, they can't speak better than the teacher,

N: Yeah

M: So they purposely dumb it down.

N: Yeah, ima wa mou sou demo nai kedo ne.

$\mathrm{N}$ : And so group of us just get together, and its its hontou ni champon ne, its like *, you know Japanglish to ka sa, Englinese hanashite mitai na kanji, so

D: The parents of children who are Hafu to be specific

$\mathrm{N}$ : Yeah 
$\mathrm{N}$ : I'm not gonna speak the language and the family or the ojiichan obaachan, or they said you're American you know, speak the language.

M: Well actually some kid some kid was doing about the Half, * the *Japanese-American Hafu split, so that was elementary school, so.

M: Andre-kun's (?) Mou jikan kitta tte.

\section{$\underline{\text { Group } 2}$}

$(0: 06)$

S: Okay so *should we proceed in English or in Japan/ese, or

Y: * Watashi, * ie, watashi wa docchi/ra de ee ka na, watashi no hou wa * i/i kedo,

H: Mama no oto wa kekko waru/i

Y: *Shit/te/(i)/ru, * watashi no hou o (?), kiko/e/niku/i no. Daijyoubu ka na? * S-/san ga,

S: Hai?

Y: * Oto Oto wa daijyoubu ka shira

$\mathrm{S}:{ }^{*}$ Kekko, * oso/i te i/u ka, chotto kiki, kik/e kik/e, * kik/e/ru koto wa kik/e/ru desu kedo, tabun intaaneto no konekushion ga waruk, waru/i mita/i ni

Y: *Yappari. *Sou sokka

S: Sore wa, * kompuuta de tsunagatteru n desu ka? Keeburu desu ka?

Y: Hai watashi wa * kompuuta desu.

S: Jyaa, ugokasenai n desu ne

Y: *Iya (1)

S: She sounds very lethargic.

Y: Dou shiyou? 
S: Demo jikan are desu shi, kore de zokko shimashou ka.

Y: Kore de yatte mimashou ka

Me: Yoroshikeredo (sic) onegaiitashimasu

Y: Onaji oto o dashi ni, ie, chotto matte jya watashi mo kittemo onnaji desu yo ne, tabun

$\mathrm{S}:$ Ma docchira ka, * comfortable no hou ni

S: Ima wa * Iuиesu no Amerika no gavamento no kontorakutaa o yattemasu.

H: Otoosan ga Neevi de, * Nihon ni wari to, tootaru jyuu nen datt, jyuu nen de, sono ato ni * (?) no okaasan to deatte, kekkon shite, sore de watashi umarete, * Yokohama de umarete, * rokusai made Nihon ni imashita.

H: Watashi no danna mo miriterii dakara, watashitachi wa kekko hikkoshi ga oookute, * ima mo moosukoshitara, * ima wa genzai Furorida ni sunderun desu kedo, * rai raigetsu ni wa * Cariforunia ni * hikoshimasu. Demo, sore irai ni mo, tekisasu ni mo hikkoshita koto mo arimasu shi, ato ni Italia ni san nen, * sundeimashita.

S: Well well, thank you for your service!

$\mathrm{H}:(?)$

S: Dakara uchi wa kekkou tipicaru na miritarii te iu yori ka wa, boku wa, * otouto to imoutou mou irun desu kedo, * mo neesan mo Yokota shika sunda koto nain desu ne.

S: Dakara, tipicaru na miritarii buratto mitai na, * seikatsu wa bokura sankyoudai wa shita, shitenai desu ne. 
H: Sukoshi chiisai toki * ni fune ni ittari to ka wa shita mitai nan desu kedo, neevi datta, demo sore igai wa *, iro iro to hikosshita, ima wa, genzai wa watashi soroete mou neevi no (?)

S: Demo benefitto ii desu kara ne,

H: Sou...

S: Uchi no oyaji mo mou iya da iya da, tsutte, mo kekkyoku nijyu-kyuu nen tsutomemashita kara ne.

H: Mada nijyuu-tsuu (?) benefittsu to ka iro, ma ii koto mo aru, aru kara maa, muzukashii...

S: Muzukashii desu yo ne, mm. Toku ni ima nanka mou miritarii iyagara hito mo ooi mitai desu shi

$(16: 50)$

H: Miriterii no hou kara mo nanka hitsuyou ga nai mitai ni

S: Beesu no gakkou ni iki hajimetan desu kedo

S: Gojyuudai ni natte, chotto, nante yuun desu ka ne, kono bairinguaru seikatsu

S: Demo kanojyou mo keeko * bairinguaru de

S: Futsuu no tipikaru na ${ }^{*}$, ma, gaikokujin no you na kanji

Y: Toku ni beesu to ka jya naku ne, soto ni sundeta kara

Y: Beesu no naka no (?) shaberu you natte 
(26:09)

S: Supaabaiza tte yuu no ga, ma mochiron Amerika-jin de, kocchi umare kocchi sodachi dattan desu kedo

$\mathrm{H}$ : Moshi, iya, miriterii no mamma

\section{Group 3}

\section{K: Hi! Konnichiwa}

\section{L: Konnichiwa}

S: Konnichiwa! So do you speak in English or Japan/ese.

L: Japan/ese, I believe

S: Yeah?

L: Nihongo

S: Nihongo

K: Wait

L: Watashi wa L to moushi/mas/u. Yoroshi/ku o/nega/i/shi/ma/su

$\mathrm{K}:$ I I speak * most/ly in English.

S: Okay

L: Okay

$\mathrm{K}$ : But I can understand Japan/ese. It is just my Japan/ese speak/ing skill/s, like my grammar is terrible, and I do/n't know like the difference between like polite talk and like what my parents use to talk to me, so like I try not to speak in Japan/ese to people that I do/n't real/ly know cause I/'ll just be rude.

L: Oh my gosh, that/'s fun/ny. * I I just learn/ed keigo, I/'m I/'m half Japan/ese, * my mom is Japan/ese and my dad is very America/n. So, I grew up here but I also grew up a little bit in Tokyo and stuff and * it's taken me awhile to get used to keigo. You definitely don't, you really have to like drill it in and learn it. 
L: We're all Nisei, is that correct?

S: And so do th what what language do they speak?

K: In the house? Just Japanese.

S: Aa, sou. (?) I speak Japanese at home. Of course, since my husband is Japanese.

L: I also went to like nihonjin-gakkou

S: Oh, nihonjin-gakkou

L: Yeah, and it was, I hated it when I was younger cause it was every Saturday

S: Because * my son, he went to Japanese school all the way up til Shougakko no owari? Chugakkou? He didn't go into chugakko.

L: Un

S: Because you know it's Saturdays

$\mathrm{S}:$ But *, he he learned kanji, you know, kanji Jap-, kanji Jap-, Nihon no kanji, * through manga.

L: Ohhh.

S: Cause he wanted to he he wanted to read manga, and in order to read manga, he he had to know kanjis.

S: It's so difficult for me too, to write * muzukashii kanji, correct, you know choosing a correct, writing a kanji is very difficult for me too.

S: Mhm 
L: *And the other day one of my coworkers who's also he's fully Japanese, but he's only spoke, spoken a- in his house and he hasn't written or read anything

S: Mhm

L: So he's thirty years old and * they were looking at a recipe book and it said komugiko,

S: Uh huh

L: And he was like what is this kanji I I I never seen this before. And I was like that's flour.

S: Uh huh

K: I feel like after Nisei, (?) like you know there's Issei, Nisei, and then you know the further away you get from Japan, the less you have of the language and the culture and I just don't want that.

S: Mhm mhm

K: Do you get praised when you go to Japan, they're like oh my gosh your Japanese is so good?

L: Yeah yeah, they're like what so did you live here like what's your deal? And then I'm like Ahh, I'm actually like I'm like haafu desu! And they're like waaaaaoh! *But, even my own family members once, I went to *, my grandma's side of the family, lives very like i-in inaka, and * I met them but there was like twenty of us and it was my grandma's side that I had never met before. And so I was the only person in the room that looked like out of place.

S: Yeah, but don't you get frustra- frustrated, when a conversation gets really deep with your relatives, or, you know because since they don't understand English, you you speak Japanese or

L: Yeah, *

S: You know konnichiwa, sayonara, kirei ne so and so it's okay?

L: But I I speak, I speak fluently um 
L: Something I love is the humor, and like the tv, like I love watching like you know like warai bangumi

S: The the the lifestyle is totally different, and the culture is really deep and the food i-

$\mathrm{K}$ : I like the food!

S: The food is really good! Oishii zettai oshii.

$(26: 07)$

$\mathrm{K}$ : Wait what part of Japan is that?

L: It's in Ibaraki-ken, it's like it's like an hour and a half outside of Tokyo.

K: Okay

$(27: 45)$

L: *S-san, do you get to go back?

L: She lives right near Omozawa daigaku.

$\mathrm{K}$ : We've been in Japan for every season except for that beautiful like time dur- like I wanna go there, I wanna go to Kyoto, and I wanna see all the the leaves falling and sit in an onsen

L: Yeahhh!

S: Kyoto is very beautiful

K: I know I wanna see it in the fall.

S: Mhm. 
Interview results

\section{Group 1}

M- [positive] Enjoys speaking JP, culture, enjoy sense of community, even exclusiveness.

[outsider] Always feeling excluded in both America and Japan, experiences in army, both as woman and as Hafu. Also feels like she overcame and used experiences to forge own path.

[comfort/intimacy] Feels immediate connection with other Hafu or even other Asians.

[culture] Overwhelmingly on the side of Japanese language as more cultured, based on age of civilization, on high context, and on degrees of politeness.

[retention] Found media to help with retention of Japanese.

N- [positive] Helped her gain employment with Nikkei businesses.

[outsider] discrimination in Japan, in US, thought of as ethnic Japanese, result is identity questions, being asked by men in college "what are you?"

[comfort] Pretty much both, but English is most comfortable in all honesty. However, emphasizes that she feels good with either.

[intimacy] English with immediate family, including children, and close friends. Hafu community does exist in SoCal, then uses code-switching. Perhaps used to speak Japanese or code-switching with mother.

[culture] English is international, Japanese is more "cultured" if you count culture as exclusivity. At my prompt, defining culture as educated, then she took the side of English, because of its use in international business and education.

[retention] Still employed for Nikkei company, so used in livelihood, communication with friends through social media and LINE, considers Japanese mother tongue.

D- [positive] Larger possibility for friendships, especially those who have spent much time in Japan. She appreciates the experience of knowing those who are very familiar with Japanese culture. At times, she feels like she is left out of the group of those who know Japan well. Visits Japan frequently, enjoys visiting those whom she knows there. Credits Facebook, other social media for connecting her with other relatives in Japan.

[outsider] Misses small elements of Japanese courtesy, e.g. shoe courtesy, overuse of sauce. Also respects low context in Japanese, frustrated by direct speech, as used to 
Americans. Also feels that she at times does not understand "more Japanese" speakers' context speech.

[comfort] Wants to be fluent in Japanese, generally understands Japanese media, except for technical speech. Significantly more comfortable with English. At times makes mistakes with keigo.

[intimacy] English, since most people who are familiar with her speak this. Spoke codeswitching with mother. Complete English with younger siblings. Would alternate between two forms.

[culture] Loves both, but has personal affinity for Japanese, based more on unequal ability. Most academic or classical culture has been in English, so does not know classical Japanese culture well.

[retention] social media, also communiqués with relatives in Okinawa, especially through electronic translator, where she double checks Japanese, which she cannot read in its entirety, with automatic reading. She understands the spoken language, which she uses to find if the sense of the kanji is correct. Also, gets feedback for letters from relatives. Loves to visit family.

\section{Group 2}

H- [positive] No negative experiences, generally positive. Specifically, getting a job with Japanese. Is called upon to share culture with others, even. High demand, with little supply. Curiosity is pleasant experience, she attributes others' bad experiences to time and place.

[outsider] Since her connection to Japan was constant, she felt comfortable in America. Only outsider experience is very miniscule, husband presumes that she is "American" when in reality, there are real cultural differences.

[comfort] Normal conversation feels great either way. Academic or professional speech is still on the side of English. Has some proficiency and experience with professional speech and keigo.

[intimacy] Speaks Japanese to son, family (can speak Japanese 50/50 with family). Also with Japanese speakers in military (apparently the military base in Italy had large group, as opposed to US).

[culture] Prefers Japanese, because of social registers, keigo, she also likes the playful speech of younger speakers, as distinct from US slang, which she claims does not change enough.

[retention] Attributes it to mother's influence, and constant positive interaction with her in Japanese, throughout life. She then brought son into picture, as well as job, and 
Japanese language groups, and other speakers met throughout casual events, and military life.

S- [positive] Helped with gaining employment, more personally, likes to use Japanese for privacy, when badmouthing others, which also gets done to him by Japanese in Japan.

[outsider] Being Half Japanese and Black has especially been hard. Was alienated by either culture, especially as a child. As adult, or professional, no significant bad experiences.

[comfort] Not currently professionally using Japanese, speaks Japanese with wife and mother, no children. Self-described "homebody", relatively isolated. Conversation group was first time speaking Japanese with majority group in a while. According to self, comfortable with "neither or both". Feels frustrated with weakening of Japanese abilities.

[intimacy] Mother, wife Japanese, everyone else in family, English, however meets Japanese speaking family more frequently (texts wife in English).

[culture] Considers English as American English. Does not know Western or European culture or history. He looks to Japan's history as older, and therefore more cultured.

[retention] Professional environment, wife are helpful, birth in Japan and education is important, but even more so, necessity for learning Japanese to speak with mother.

Y- [positive] Initially responds that she likes understanding English movies and dramas. Understands both languages. Enjoys company with Japanese friends in US. Helps friends with English in America, as well as teaching Japanese.

[outsider] No issues. Occasionally, has miscommunication, but that's all. Hears other people have troubles, but no concern.

[comfort] Prefers Japanese.

[intimacy] English to husband, Japanese to daughter, but she is not around immediately, so she actually usually uses English more frequently.

[culture] Wonders if this should be considered "kotobateki" (in terms of words)? And personally? If so, then prefers Japanese, since she is used to it, but likes multiplicity of meanings in words. Feels like there is more culture in Japanese.

[retention] She loves to talk, and returned to Japan frequently, talks to Japanese friends and daughter. Also likes anime and manga and Japanese books. More passive than not. Recently began to lose some vocabulary, and is helped by daughter.

\section{Group 3}


S- [positive] Enjoys privacy with fellow speakers, does speak with friends, occasionally code-switches into English with those who are familiar. English may be the insider language for certain of her Japanese friends. But she also appeals to connotations that are not found in English through Japanese.

[outsider] Not much. In context with Black culture, she feels like an outsider, unable to follow speech.

[comfort] Prefers Japanese.

[intimacy] Japanese. In the group conversations, she explained that she considers herself essentially Japanese.

[culture] She feels Japanese is more cultured, but depends on context. Japanese allows for more ambiguity, so she feels that it is not suited to precise conversation, unlike English. However, because of history, again, she brings up that there are more proper names for objects, since there is an enormous cultural deposit of these things. (I.e. names of fish, flowers, having seasonal names) She however, claims that this also applies to English, in which there are more names for things unique to that culture, like chairs. I sum this up by saying that culture is "the ability to express nuances."

[retention] More concerned about going to Japan and losing English. Feels her Japanese is slipping away. At times, feels that English comes more quickly, or is "champon." Also speaks to Japanese speakers.

L- [positive] gained employment, gets connections, which sometimes lead to jobs. Grateful to keigo for these connections. Useful as novelty to non-Japanese speakers, useful to speaking to mother, maintaining connections. Considers herself "ethnically ambiguous." Thinks that Japan has become a "trend." When growing up, this culture was not accepted. However, more recently, she feels that it will probably be more acceptable.

[outsider] Like other Halfs, she feels that she does not fit in either culture. At first, language is cause. She says she grew up in mainly American culture. Still "finding my people." She senses racism towards mother occasionally. Brings up situation with brother in which he gets aggressed by driver for being foreign looking. As a child, she feels that "she had left my identity at the door," stopped speaking Japanese for a time.

[comfort] Prefers English, since more experience with it, but feels that she speaks Japanese satisfactorily (low expectations) but succeeds at job (higher expectations). Sometimes encounters "mental blocks" with Japanese, like politics and emotions. Caused a bit of trouble with mother about these things. She also includes reading Japanese as well.

[intimacy] Used to speak Japanese with brother, in Japan, had English as inside language. Now more English than not. English with father. Japanese with mother. (Each language is exclusive with each parent) With extended family, language depends on the country. 
[culture] Japanese is cultured, because no need to mention self as subject when speaking. Can accommodate different listeners. Respects "collectivist" aspect of Japanese. Also, likes how Japanese incorporates other languages from other cultures. Likes how Japanese takes more time to borrow words that are closer to the original language: such as "Doitsu" and "Pari." Feels that English is "wild language" with few rules, does not feel that it even has a culture.

[retention] Yes retained, but she feels she very nearly lost it in middle school and above. She actively needed to maintain it. Her job and Japanese school helped in this process. Her experience at the business Japanese school helped her. Does not consider herself fluent, but is "kind of native."

K- [positive] Gets to impress non-speakers in America. Gets to give superior translations of anime and other things, to be the authority. In Japan, gets to surprise natives. Struggles with speaking occasionally. Overwhelmed by Kansai dialect.

[outsider] Not language based, but sometimes embarrassed by parents' inability with friends, sometimes culture shamed by outsiders, such as food at school (L also said this) However, in high school, Japanese food became acceptable by others. (She attributes this to age, not time period)

[comfort] Absolutely English is better. Sometimes likes specific phrases in Japanese.

[intimacy] Also English, cause easier. Parents could only speak Japanese (father sometimes speaks English, but not mother functionally) Spoke English to parents despite this.

[culture] Japanese, on the supposition that the less known language is more unfamiliar, also brings up supposedly larger vocabularies in other languages.

[retention] Lost much Japanese, used to speak as a child. Has trouble with grammar. After losing speaking ability, she feels that her constantly listening to Japanese has kept her understanding ability, in family as well as in anime. When asked how she lost it, she answered that her school experience destroyed her Japanese. Her parents emphasized learning English, used educational materials for English. Because of their low proficiency, they were concerned their children would not speak proper English. 